\title{
ToxCast chemical library screen identifies diethanolamine as an activator of Wnt signaling
}

\author{
Justin M. Wolter ${ }^{1,2,3}$, Jessica A. Jimenez ${ }^{4}$, Jason L. Stein ${ }^{1,5}$, Mark J. Zylka ${ }^{1,2,3 *}$
}

${ }^{1}$ UNC Neuroscience Center, The University of North Carolina at Chapel Hill, Chapel Hill, NC 27599, USA

${ }^{2}$ Department of Cell Biology and Physiology, The University of North Carolina at Chapel Hill, Chapel Hill, NC 27599, USA

${ }^{3}$ Carolina Institute for Developmental Disabilities, The University of North Carolina at Chapel Hill, Chapel Hill, NC 27599, USA

${ }^{4}$ Curriculum in Toxicology \& Environmental Medicine, The University of North Carolina at Chapel Hill, Chapel Hill, NC 27599, USA

${ }^{5}$ Department of Genetics, The University of North Carolina at Chapel Hill, Chapel Hill, NC 27599, USA

Running Title: ToxCast library screen identifies DEA as Wnt activator 


\section{$\underline{\text { Abstract }}$}

Numerous autism spectrum disorder (ASD) risk genes are associated with Wnt signaling, suggesting that brain development may be especially sensitive to genetic perturbation of this pathway. Additionally, valproic acid, which modulates Wnt signaling, increases risk for ASD when taken during pregnancy. We previously found that an autism-linked gain-of-function $\mathrm{UBE}^{\mathrm{T}} \mathrm{A}^{\mathrm{T} 485 \mathrm{~A}}$ mutant construct hyperactivated canonical Wnt signaling, providing a genetic means to elevate Wnt signaling above baseline levels. To identify environmental use chemicals that enhance or suppress Wnt signaling, we screened the ToxCast Phase I and II libraries in cells expressing this autism linked $U B E 3 A^{T 485}$ gain-of-function mutant construct. Using structural comparisons, we identify classes of chemicals that stimulated Wnt signaling, including ethanolamines, as well as chemicals that inhibited Wnt signaling, such as agricultural pesticides, and synthetic hormone analogs. To prioritize chemicals for follow-up, we leveraged predicted human exposure data, and identified diethanolamine (DEA) as a chemical that both stimulates Wnt signaling in $U B E 3 A^{T 485 A}$-transfected cells and has a high potential for prenatal exposure in humans. DEA also enhanced proliferation in two primary human neural progenitor cell lines. Overall, this study identifies chemicals with the potential for human exposure that influence Wnt signaling in human cells.

\section{$\underline{\text { Keywords }}$}

Wnt signaling

ToxCast

Diethanolamine

Neural progenitor cells 


\section{Introduction}

Large-scale exome sequencing studies of individuals with autism identified over 100 high-confidence ASD genes(1-3). Approximately $19 \%$ of these ASD genes are associated with the Wnt/ß-catenin signaling pathway, suggesting that alterations in Wnt signaling contribute to ASD pathogenesis(4-9). Members of the Wnt family are secreted signaling proteins that affect the development of nearly every area of the central nervous system(10). In the developing brain, Wnt establishes the anterior/posterior and dorsoventral axes, and instructs cell fate decisions by regulating the balance between differentiation and proliferation(11). Constitutive activation of Wnt signaling leads to hyperproliferation of neural progenitor cells and macrocephaly(12).

Non-genetic environmental factors also contribute to autism risk(6, 13, 14). Epidemiological studies link gestational exposure to agricultural pesticides with risk for $\operatorname{ASD}(15,16)$. And, certain environmental-use chemicals can mimic transcriptional changes associated with ASD when applied to primary mouse neuron cultures $(17,18)$. The best characterized environmental risk factor for ASD is valproic acid (VPA), which is prescribed for epilepsy, bipolar depression, and migraine(19). Prenatal exposure to VPA increases the risk of congenital malformations(20), $\operatorname{ASD}(21,22)$, and macrocephaly(23, 24). VPA activates Wnt signaling by targeting HDAC1(25). Furthermore, drugs approved by the FDA for treating behavioral symptoms of ASD (aripipazole, risperidone) can affect Wnt signaling $(26,27)$. These studies suggest that the developing nervous system may be highly sensitive to chemicals in the environment that modulate Wnt signaling.

Identifying environmental risk factors for neurodevelopmental disorders is a major challenge due to the lack of developmental neurotoxicological data on the vast majority of chemicals(28). To address this critical need, the EPA created the Tox 21 program, which aims to provide platforms and methods to rapidly screen chemicals for potential adverse health effects(29). Here, we hypothesized that Wnt modulating chemicals will have enhanced effects in cells expressing an ASD-linked gene that, when overexpressed, stimulates Wnt signaling. To test this hypothesis, we screened the EPA Toxcast Phase I/II libraries using a Wnt sensitive luciferase reporter(30) in cells overexpressing UBE3A with an autism-linked T485A mutation ( $\left.U B E 3 A^{T 485 A}\right)$, a mutation that promotes Wnt signaling $(31,32)$. 


\section{$\underline{\text { 2. Materials and Methods }}$}

\subsection{Lentiviral infection of primary mouse cortical neurons}

All lentivirus was produced in HEK293T cells using the third-generation packaging plasmids(33). Supernatant was collected, filtered using $0.45 \mu \mathrm{M}$ filters, and frozen in single use aliquots.

Primary neuron cultures from E15.5 C57Bl/6 mouse embryos were prepared as previously described(18). Neurons were plated in 96 well plates at 20,000 cells per well. On day three, cells were infected with lentiviruses carrying BAR:luciferase and Tk:Renilla in a 5:1 ratio. Cells were incubated for five days, then treated with ToxCast chemicals and incubated for 48 hours. Cells were lysed and the lysate was used in dual luciferase assays using the Dual-Glo luciferase system (Promega), and measured on the GloMax Discover plate reader (Promega).

\subsection{High-throughput Wnt screen of ToxCast phase I/II libraries}

All liquid handling steps of HEK293T ToxCast Phase I/II screen were performed using the Tecan EVO liquid handling robot. These steps included cell plating, chemical library dilution and aliquots, cell dosing, transfections, and luciferase assays. Technical replicates for six control chemicals (three Wnt inhibitors and three Wnt activators) were spiked into random positions in each plate to ensure technical reproducibility and eliminate the risk of plate swaps. HEK293T cells were cultured in DMEM (Gibco) and 10\% FBS in the absence of antibiotic in a humid incubator at $37^{\circ} \mathrm{C}$ with $5 \%$ (vol/vol) $\mathrm{CO}_{2}$. Cells were plated in white opaque 384 well plates at a density of 4,500 cells per well. 24 hours post plating cells were transfected with a $\beta$-catenin responsive luciferase reporter (BAR)(30), TK-Renilla, and pCIG2 UBE3A ${ }^{T 485 A}$ using Fugene 6 (Promega). 4 hours post transfection cells were treated with chemical libraries. Cells were lysed 24 hours later, and luciferase assays were performed using the Dual-Glo luciferase system (Promega). All steps, including cell culture, treatments, lysis, and luciferase assays were performed in the same plate to minimize technical variation from handling artifacts. Four biological replicates (one well per chemical per concentration per day) were performed on different days to ensure reproducibility and reduce batch effects.

\subsection{Screen analyses}

The "Wnt luciferase ratio" was calculated by dividing the raw Firefly value by the raw Renilla luciferase value, and median centering within each plate. "Cell Health" was calculated using the raw Renilla value median centered within each plate. Biological replicates were averaged, and $P$-values were calculated using a two tailed 
T-test. To calculate the "Wnt Score" (Wnt activity with a penalty for toxicity) we calculated the mean log2 fold change of the Wnt luciferase ratio for each chemical, calculated the slope of the concentration-response curve for that chemical, and multiplied this by the mean of the Cell Health metric. The EPA spiked in replicate chemicals across plates to assess reproducibility, in addition to the six control chemicals we added. When a chemical was present in multiple plates we averaged the values for each metric.

\subsection{HEK293T versus neuron toxicity comparison}

RASL-seq assessed Toxcast Phase I chemical toxicity in primary mouse neuron cultures by spiking in control luciferase RNA in each well, and calculating the ratio of luciferase reads to total number of reads from neurons(18). We normalized this data by median centering and averaged the values for all concentrations of each chemical. We then compared the measure of cell health from primary neurons to the Cell Health Metric from this screen.

\subsection{Structural chemical clustering}

Chemical structuring was performed using ChemMineR(34). SMILE strings were converted to SDF files. Distance matrices were defined using atom-pair properties, and unsupervised hierarchic clustering was performed using $\mathrm{R}$.

\subsection{Estimated human exposure data}

Estimated human exposure data was downloaded from(35). We compared the Wnt Score metric with the 95\% confidence interval $\mathrm{mg} / \mathrm{kg} /$ body weight/day for reproductive age females (defined as 16-49 years old), reasoning that this demographic is most representative of maternal, fetal, and neonatal exposure.

\subsection{DEA in HEK293T cells}

DEA was obtained from Sigma-Aldrich (\#31589). The panel of luciferase reporter plasmids was a kind gift from the lab of Dr. Ben Major. Luciferase assays were performed as described above. The following day cells were transfected with either pCIG2:empty (eGFP with an IRES carrying empty sequence) or pCIG2 $U B E 3 A^{T 485 A}$. Four hours later cells were treated with the indicated concentrations of DEA or vehicle (DMSO). Cells were incubated for $48 \mathrm{~h}$ and then total RNA was extracted using Trizol. cDNA was synthesized using SuperScript IV VILO with ezDNase (ThermoFisher). qPCR experiments were performed using SsoAdvanced Universal SYBR Green Supermix (NEB) on the Quantstudio5 (Applied Biosystems). Data was normalized to 
EIF4A2 using the $\triangle \triangle \mathrm{Ct}$ method. Two-tailed t-tests were used for comparison between vehicle conditions, and two-way ANOVA was used for concentration-response curves.

\subsection{Primary human neural progenitor cell cultures}

Human fetal brain tissue was obtained from the UCLA Gene and Cell Therapy Core following IRB regulations. Primary human (ph)NPCs were grown and differentiated as previously described(36, 37). Briefly, cells were thawed and plated in $10 \mathrm{~cm}$ plates with proliferation media (Neurobasal A supplemented with primocin, BIT9500, glutamax, heparin, EGF, FGF, LIF, PDGF) in a humid incubator at $37^{\circ} \mathrm{C}$ with 5\% (vol/vol) $\mathrm{CO}_{2}$. Cells were mycoplasma tested and confirmed to be mycoplasma free (ATCC, Universal Mycoplasma Detection Kit). For experiments in Supporting Figure 1b cells were plated in 96 well plates and infected with lentivirus carrying BAR:luciferase and Tk:Renilla in a 5:1 ratio. Cells were incubated for 48 hours, then treated with the indicated chemicals. Cells were incubated for an additional 48 hours, then lysed and subjected to dual luciferase assays, as described above. For experiments in Figure 5 cells were plated in 96 well plates at a density of 12,500 cells per well. 24 hours later cells were treated with DEA, and incubated for 46 hours. We then performed a two-hour pulse with $10 \mathrm{uM} \mathrm{EdU,} \mathrm{then} \mathrm{fixed} \mathrm{the} \mathrm{cells} \mathrm{with} \mathrm{4 \%} \mathrm{paraformaldehyde.} \mathrm{Labelling} \mathrm{was} \mathrm{performed}$ using the Click-iT EdU fluorescent labeling kit per manufacturer's instructions (Thermo-Fisher Cat. C10337). DNA was labeled using FxCycle Far Red stain (Invitrogen, Cat\# F10348). Cells were counted using the Attune NxT. Data was analyzed using the FlowJo software. 


\section{Results}

\subsection{High-throughput screen for environmental-use chemicals that modulate Wnt signaling}

Given the evidence implicating Wnt signaling in ASD pathogenesis, we set out to test the EPA ToxCast Phase I and Phase II libraries(38) in cells transfected with an ASD linked UBE3A $A^{T 485 A}$ mutant expression construct(31). Toxcast libraries contain chemicals with the potential for human exposure, including pesticides, plasticizers, perfluorinated chemicals, and "failed-pharma" compounds, which were donated by pharmaceutical companies due to toxicity in trials(38). We were blind to the identities of ToxCast Phase II chemicals during the screen, and were only unblinded after sharing the results of our screen with the EPA.

To quantify Wnt signaling, we used the $\beta$-catenin activated reporter (BAR) luciferase reporter, which contains 12 tandem binding sites for the TCF/LEF transcription factor(30). We cotransfected a Renilla luciferase reporter driven by the Thymidine Kinase (TK) promoter as an internal control to assess cell viability and toxicity. Overexpression of $U B E 3 A^{T 485 A}$ activates the Wnt reporter by inhibiting proteasome dependent degradation of $\beta$-catenin(32). To identify a representative cellular context in which to perform the screen, we tested known Wnt activators in primary mouse cortical neurons, primary human neural progenitor cells (phNPCs), and HEK293T cells (Supporting Figures S1a-c). Control chemicals included VPA(25), the GSK3 $\beta$ inhibitor CT99021(39) and lithium chloride(40). We found context specific effects, with LiCl not activating the Wnt reporter in primary mouse neurons (Supporting Figure S1a), and VPA not activating the Wnt reporter in phNPCs (Supporting Figure S1b). HEK293T were the only cells that demonstrated Wnt activation of all three chemicals, therefore we chose these cells to perform the screen (Supporting Figure S1c). Wnt inhibitors and activators received a positive Z-factor, a statistical measure of assay suitability for high-throughput screening(41) (Supporting Figure S1d).

Our two endpoints were Wnt luciferase ratio (BAR/Renilla, Figure 1a) and "cell health" (Renilla values, Figure 1b) (see Materials and Methods). We considered putative Wnt modulators as those with log2 fold change $\operatorname{abs}(\log 2$ fold change) $>1$ compared to vehicle, and p-value $<0.05$ (Figure 1a, Supporting Table S1). All control chemicals performed as expected (arrows, Figure 1a).

\subsection{Toxicity of ToxCast phase I/II chemicals}

Many of the ToxCast chemicals exhibited concentration-dependent toxicity (log2 fold change $<-1$, and p-value $<0.05$, Supp. Table 1, Figure 1b). Previously, we tested the ToxCast Phase I library, which contains 
mostly pesticides(38), in primary mouse neuron cultures using RNA-seq as well as RASL-seq-a massively pooled transcriptomic assay $(17,18)$. In the RASL-seq experiments we also estimated neuronal toxicity by comparing total read counts per well to a luciferase mRNA spike in control. To identify chemicals with context specific toxicity, we compared the toxicity values in HEK293T cells (Figure 1b) with those in primary neurons (Figure 1c). The chemicals which were specifically toxic in HEK293T cells were mechanistically broad (Supporting Table S2), but typically exert anti-mitotic effects, such as the chemotherapeutics paclitaxel, fluorodeoxyuridine, and irinotecan $(42,43)$. Among these chemicals were also environmental use pesticides such as ametryn, the most widely used herbicide in sugarcane production and a frequent contaminant in aquatic environments $(44,45)$. In contrast to the broad mechanisms of toxicity in HEK293T cells, the chemicals that were most toxic to neurons were mitochondrial complex I and III inhibitors. These included fenpyroximate, trifloxystrobin, pyridaben, fenazaquin, and pyraclostrobin (Figure 1c, Supporting Table S2)(46, 47). This class of chemicals is functionally related to rotenone (Supporting Table S2), which is implicated in Parkinson's disease $(48,49)$. Emamectin benzoate, a chemical that binds with high affinity to invertebrate GABA receptors $(50,51)$, was also selectively toxic in mouse neurons.

We next compared Wnt modulation with toxicity, and found that many chemicals that activated or inhibited the Wnt reporter were also toxic (Figure 1d). This is in contrast to our control chemicals which modulated Wnt without strong toxicity (Figure 1d, Supporting Figure 2a,b). Therefore, we generated a metric termed the "Wnt Score," which reflects the potency of each drug across multiple concentrations with a penalty for toxicity (See Materials and Methods, Supporting Figure S2). All the control chemicals segregated to the top of this list (Figure 2a). To identify high-confidence non-toxic Wnt modulators, we filtered for those with $\mathrm{p}<0.05, \log 2$ fold change greater than abs $(\log 2$ fold change $)>1$, and Wnt score $>0.4$.

\subsection{Structural and functional comparisons of non-toxic Wnt modulators}

Structural comparisons of chemical libraries can be used to group chemicals with similar structures to infer common functions and molecular targets. To characterize structural similarities in the ToxCast chemicals, we used SMILE strings to performed hierarchical clustering and multidimensional scaling(34). The most potent Wnt activator in the Toxcast library was pharmaGSID_48505, which has structural similarity with CT99021 (Figure 2b, Supporting Figure S3a,b). The similarity in effect size and structure between these two molecules suggests pharmaGSID_48505 targets GSK3 $\beta$, but the enhanced toxicity suggests it is not as specific as CT99021 (Supporting Figs. 3a,b). The next cluster of Wnt activators contains several forms of ethanolamine (Figure 2b,c). Ethanolamines are bifunctional chemicals, containing a primary amine group and a primary 
ethanol group. Ethanolamine forms the head group of the phospholipid phosphatidylethanolamine, which is highly abundant in the inner leaflet of cell membranes(52), and comprises $\sim 45 \%$ of all phospholipids in the brain(53). Both ethanolamine and diethanolamine (DEA) activated the Wnt reporter without toxic effects (Figure 2c), while triethanolamine had no effect (Supporting Figure S3c). DEA has marginal structural similarity to VPA (Figure 2b). Clopyralid-olamine, a mixture of clopyralid and ethanolamine, also activated the Wnt reporter (Figure 2c). However, clopyralid alone had no effect (Supporting Figure S3d), suggesting that ethanolamine in this mixture was responsible for activating the Wnt reporter.

Wnt inhibitors were substantially more numerous than activators, highlighting the benefit of screening the Wnt reporter in cells transfected with $U B E 3 A^{T 485 A}$, which activates Wnt signaling (Figure 3a). Multiple agricultural pesticides inhibited the Wnt reporter, and these were structurally diverse (Figure 3a). These included the mitochondria complex I inhibitor tebufenpyrad (Figure 3b), and flufenacet, which inhibits synthesis of very long chain fatty acids (Figure 3c)(54, 55). Three inhibitors of p38 were also identified (Figure 3a), including CP-863187 which is a highly potent and selective p38 inhibitor (Figure 3d)(56). P38 regulates the canonical Wnt pathway through GSK3 $3(57)$, again highlighting GSK3 $\beta$ as a central regulatory node of the Wnt pathway. Four clusters resolved when comparing chemical similarity, including synthetic estrogens (Figure 3e), thyroid hormone analogs (Figure 3f), glucocorticoid and steroid hormones (Figure 3g), and agricultural fungicides (Figure 3h). The crosstalk between these hormone signaling pathways and Wnt signaling is well established(58-62). These results raise the possibility that exposure to multiple chemicals with structural and functional similarity might have additive effects by acting through the same molecular pathways.

\subsection{Prioritizing chemicals using predicted human exposure data}

Humans are exposed to thousands of environmental-use chemicals, yet exposure data is not available for the majority of these chemicals(63). Instead, exposure estimates can be generated using various parameters, including urine biomonitoring of representative chemicals, chemical use classes, and production volume(35). We used these estimates to prioritize chemicals for more detailed validation experiments (Figure 4). We focused on exposure (mg/kg/body weight/day) predictions for reproductive age (16-49) females, reasoning that this age group best represents in utero exposure estimates (Figure 4, Supporting Table S3). The inhibitor with the highest relative exposure predictions was FD\&C Blue No.1 (Figure 4). This dye has been approved for use in foods since the early 1900's, and is considered safe and non-toxic by the FDA. It is deep blue in color, which visibly altered the color of cell media, which could interfere with the sensitivity of the luciferase assay. For these reasons we did not pursue this chemical for further experimental validation. 
The next Wnt modulator with high exposure predictions was DEA, which was in the 98th percentile of predicted exposure volume for all $\sim 8,000$ chemicals in the Tox21 set (Figure 4)(35). DEA is used in a wide range of products, including adhesives, printing inks, paint, pigments, and paper, among others (64). DEA is capable of absorbing through the skin, therefore the most likely route of human exposure is dermally through liquid laundry and dish detergents, shampoos, and soaps $(64,65)$, where it functions as a surfactant and $\mathrm{pH}$ adjuster(66). It is also used in manufacturing, where it is estimated that $\sim 800,000$ workers are exposed to DEA through occupations such as metalwork and road paving(64). There is inadequate epidemiological data for DEA exposure in humans, but DEA is classified as possibly carcinogenic in humans based on animal models(67), where dermal exposure demonstrates carcinogenic activity(68). DEA accumulates in specific tissues following repeat exposure, including the brain, where it is incorporated into phospholipids(69). DEA has also been shown to influence hippocampal neural progenitor proliferation at high doses in vitro(70) and in vivo $(71,72)$.

DEA is structurally similar to endogenous ethanolamine and choline. Cells and animals treated with DEA phenocopy choline deficiency, likely via competitive inhibition of choline metabolism(70, 73). However, there are no previous reports linking DEA to Wnt signaling, nor to any other developmental signaling pathways. For these reasons we decided to focus on DEA in follow up experiments. Using commercially obtained DEA, we tested the specificity of DEA in HEK293T cells against luciferase reporters that are sensitive to various signaling pathways. DEA concentration-dependently activated the Wnt reporter, with slight but statistically significant activation of the TGF $\beta$ reporter (Figure 5a). Wnt and TGF $\beta$ share many downstream target genes, and components of the two pathways are known to interact(74).

We next tested whether genetic background influenced the activity of DEA. We transfected HEK293T cells with either an empty plasmid, or one containing the autism linked $U B E 3 A^{T 485 A}$ mutant construct, and tested the effect of DEA on the Wnt reporter over a wide range of concentrations. Notably, DEA activated the Wnt reporter at 100-fold lower concentrations when transfected with $U B E 3 A^{T 485 A}$ (Figure 5b). DEA has previously been shown to decrease proliferation and increase apoptosis of mouse NPCs in vitro and in vivo(70, 71). In vivo, DEA affects hippocampal NPC proliferation at $80 \mathrm{mg} / \mathrm{kg}(71)$, which is substantially higher than what is predicted for human exposure ( $\sim 0.0038 \mathrm{mg} / \mathrm{kg}$ bodyweight per day). Therefore, we sought to determine the lowest concentration at which DEA alters NPC proliferation using two genetically distinct phNPC lines(36). We compared DEA to known chemical Wnt modulators, including the Wnt activators CT99021, and lithium chloride. Each of the control chemicals increased proliferation as expected (Figure 5c,d). DEA increased proliferation in a concentration dependent fashion; the magnitude was similar to that of lithium chloride (Figure 
bioRxiv preprint doi: https://doi.org/10.1101/2021.02.15.430319; this version posted February 15, 2021. The copyright holder for this preprint (which was not certified by peer review) is the author/funder, who has granted bioRxiv a license to display the preprint in perpetuity. It is made available under aCC-BY-NC-ND 4.0 International license.

$5 \mathrm{c}, \mathrm{d})$. DEA was active at the lowest concentration tested $(50 \mu \mathrm{M})$ in one cell line. We observed that higher concentrations were noticeably toxic to phNPCs (Figure 5d). 


\section{$\underline{\text { Discussion }}$}

Here, we screened a library of environmental-use chemicals for their ability to modulate a Wnt sensitive reporter in cells overexpressing $U B E 3 A^{T 485 A}$, an autism-linked gene that stimulates Wnt signaling at baseline. Previously, the EPA tested the ToxCast libraries for Wnt activation using a similar TCF7 reporter construct(75). Our approach is different for two reasons. First, in HEK293T cells TCF/LEF reporters are largely not expressed above baseline levels without additional treatment, which prevents detection of Wnt inhibitors. Second, we evaluated Wnt signaling in a genetically "sensitized" background, which we hypothesized would enhance the effects of Wnt modulators.

By comparing chemical structures, we identified classes of chemicals with shared effects on Wnt signaling, including synthetic estrogens, thyroid hormones, glucocorticoid and steroid hormones, and agricultural fungicides. Aside from PharmaGSID_48505, the primary cluster of non-toxic Wnt activators were ethanolamines, which are predicted to have relatively high levels of exposure in reproductive age females and children age 6-11 (Figure 4). We found that DEA specifically activated Wnt signaling in baseline conditions, but overexpressing the autism linked $U B E 3 A^{T 485 A}$ mutation amplified DEA's effect on Wnt signaling (Figure 5). Consistent with the role on Wnt in regulating proliferation, we observed an increase in proliferation in primary human neural progenitor cells.

In animal models, DEA exposure has effects on several tissue/organ systems. Mice treated with DEA for two years develop higher rates of kidney and liver tumors (data reviewed in(65)). These tumors had high rates of mutations in exon two of the $\beta$-catenin gene, and demonstrated abnormal nuclear localization of $\beta$-catenin, indicative of constitutively active Wnt signaling(76). Topical treatment of DEA on pregnant mice reduces embryonic viability, and reduces proliferation of embryonic hippocampal neural progenitors in vivo(71). At high doses, DEA was found to reduce proliferation of cultured murine NPCs via inhibition of choline uptake(70). Choline is an essential nutrient crucial for normal brain development(77), and DEA affects patterns of DNA methylation that mimic choline deficiency(78).

There are several possible mechanisms by which DEA could modulate Wnt signaling. DEA is structurally similar to choline, and both are incorporated into phosphoglyceride and sphingomyelin analogs(69). Importantly, this unnatural incorporation includes a xenobiotic headgroup from DEA, and leads to bioaccumulation in the brain(69). The composition of the lipid membrane influences membrane localization and trafficking of lipid modified proteins(79), such as the Wnt ligands, which require lipid modification for proper solubility, the establishment of morphogen gradients, and protein interactions(80). Furthermore, the Wnt 
coreceptor LRP6 also uses phospholipids as signaling ligands(81). Thus, there are multiple possible mechanisms by which DEA exposure could influence lipid metabolism and affect Wnt signaling.

DEA is used in cosmetics due to its properties as a pH stabilizer ( $\mathrm{pH} 9.5)$. Recent experiments in the context of chick development demonstrated that high intracellular $\mathrm{pH}$ caused by enhanced glycosylation leads to non-enzymatic $\beta$-catenin acylation, which activates Wnt specific transcriptomic profiles that maintain mesoderm identity(82). Acidification of tumor cells also inhibits Wnt signaling in tumor cells(83). Furthermore, the loss of UBE3A affects $\mathrm{pH}$ of the Golgi apparatus, which compromises $\mathrm{pH}$ sensitive functions of the Golgi apparatus, such as glycosylation(84). Therefore, alterations in intracellular $\mathrm{pH}$ could be a mechanism by which DEA enhances Wnt signaling in the context of the hyperactive $U B E 3 A^{T 485 A}$ mutation.

The use of DEA in cosmetics was banned in Europe and Canada following concerns about DEA as a carcinogen $(85,86)$. The FDA and the National Toxicology Program have likewise found an association between DEA and cancer in lab animals, and provide information on the use of DEA and its derivatives in cosmetics (https://www.fda.gov/cosmetics/cosmetic-ingredients/diethanolamine). However, as of this writing, DEA is approved in the United States as long as it does not comprise $>5 \%$ of the total product composition(65). To our knowledge there have been no epidemiological studies suggesting a role, or lack thereof, of DEA in increasing risk for neurodevelopmental disorders. Our data suggests that genetic background (i.e. $U B E 3 A^{T 485 A}$ expression) greatly enhances the effects of DEA on Wnt signaling (Figure 5b), and that DEA increases human NPC proliferation at relatively low concentrations (Figure $5 \mathrm{c}, \mathrm{d})(70)$. Given these findings, the predicted high level of exposure in humans, including women of childbearing age, additional studies are warranted, particularly with regard to exposure and neurodevelopmental outcomes in genetically sensitized backgrounds.

\section{Acknowledgements}

We thank Tammy Havener and the UNC Catalyst for Rare diseases for use of the high-throughput screening facility, Thomas Girke for technical assistance, John Wambaugh for providing human exposure prediction data, and Steven Zeisel for his helpful comments.

\section{Contributions}

JMW and MJZ designed the experiments and wrote the manuscript. JMW performed all experiments and analysis. JJ performed the experiments in Figure 5A. JLS provided reagents and protocols for performing human neural progenitor cultures. 


\section{Figure Legends}

\section{Figure 1 - Screen to identify ToxCast chemicals that stimulate or inhibit Wnt signaling.}

a) ToxCast phase I/II chemicals screened against the Wnt luciferase reporter in HEK293T cells transfected with $U B E 3 A^{T 485 A}$ expression plasmid. Arrows mark chemicals that were used as positive controls. Each point is a single chemical at a single concentration. $\mathrm{P}$-value represents unpaired T-test comparing each chemical with negative control vehicle wells in each plate.

b) Cell health of ToxCast chemicals in HEK293T cells transfected with $U B E 3 A^{T 485 A}$ expression plasmid. Each point is a single chemical at a single concentration. Decrease in cell health score indicates toxicity.

c) Comparison of ToxCast chemical toxicity in HEK293T cells transfected with $U B E 3 A^{T 485 A}$ and primary mouse neuron cultures. Toxicity was calculated as the slope of Renilla luciferase (internal control) signal across all concentrations of each chemical.

d) Comparison of cell health and Wnt activation measures. Each point is a single chemical at a single concentration. Chemicals below the dashed line are those that have toxic effects.

\section{Figure 2 - Non-toxic Wnt activators}

a) Toxicity corrected Wnt luciferase ratio (Wnt Score), which combines all concentrations of each chemical and imparts a penalty for toxicity (mean luciferase ratio of all concentrations ( $\log 2$ fold change), multiplied by the mean Renilla values for all concentrations). Positive control chemicals for both activation and inhibition rose to the top of this list.

b) Comparison of chemical structures of non-toxic Wnt activators using SMILE strings and hierarchical clustering.

c) Concentration-response curves for Wnt luciferase signal and toxicity scores for the ethanolamine cluster. Values normalized to vehicle.

\section{Figure 3 - Non-toxic Wnt inhibitors}

a) Comparison of chemical structures of non-toxic Wnt inhibitors using SMILE strings and hierarchical clustering. Representative chemicals displayed in $\mathbf{b}-\mathbf{h}$ marked by asterisks.

b-h) Concentration-response curves for Wnt luciferase signal and toxicity scores for representative chemicals of each class.

\section{Figure 4-Human exposure prediction data}


Predicted exposure of reproductive age females to ToxCast chemical libraries. Chemicals with non-toxic Wnt modulation from Figures 2,3 are colored.

\section{Figure 5 - DEA activates Wnt signaling and proliferation}

a) The effect of DEA on several luciferase reporters that measure developmental signaling pathways. Experiments done in the absence of $U B E 3 A^{T 485 A}$ overexpression. Tk:Renilla cotransfected for internal control. PGK (ubiquitous promoter, negative control), Hh (Hedgehog). Data normalized to vehicle for each reporter. T-test, $* \mathrm{p}<0.05, \mathrm{n}=4$.

b) Concentration-response curve of DEA on Wnt luciferase reporter in the presence of either empty plasmid, or $U B E 3 A^{T 485 A}$ overexpression. ANOVA, effect of genotype on Wnt response, $* * \mathrm{p}<0.01$.

c,d) Proliferation rates of Wnt control chemicals and DEA in two primary human neural progenitor cell lines. Cells treated for 46 hours with indicated chemical and concentration, followed by a two hour pulse with EdU. Cells analyzed by flow cytometry. T-test, * $\mathrm{p}<0.05, \mathrm{n}=4$.

\section{Supporting Figure 1 - Establishing ToxCast screen conditions}

a-c) Chemicals known to activate Wnt signaling tested in primary mouse cortical neurons (a), primary human neural progenitor cells (b), and HEK293T cells (c), without $U B E 3 A^{T 485 A}$ overexpression. Primary cells were transduced with lentiviruses carrying BAR:Firefly and Tk:Renilla. HEK293T cells were transiently transfected with plasmids. $n=4$ per condition.

d) Z-factor analysis for known Wnt activating and inhibiting control chemicals at indicated concentrations.

\section{Supporting Figure 2 - Examples of concentration-response curves and Wnt Score}

a-c) Control chemicals that modulate Wnt reporter (solid line) at concentrations that are non-toxic (dashed line). The Wnt score listed to the right of each graph is a single score combining multiple concentrations of the Wnt reporter values with a penalty for toxicity (see methods).

d,e) Concentration-response curves for two ToxCast chemicals that significantly inhibit (d) or activate (e) the Wnt reporter, but do so at concentrations that are toxic. The Wnt score listed to the right, centered around 0 , reflects the penalty incurred on Wnt activation from toxicity. 
Supporting Figure 3 - Concentration-response curves for two Wnt activating chemicals and two chemicals that are structurally similar to activators, but that fail to activate Wnt signaling.

a-d) HEK293T cells transfected with $U B E 3 A^{T 485 A}$ treated with (a) the most potent ToxCast wnt activator pharmGSID_48505, and (b) CT99021, the most potent Wnt activator identified to date. Results demonstrate similar effect sizes with higher toxicity for pharmaGSID_48505. (c) Triethanolamine, the trimeric form of monoethanolamine, fails to activate Wnt reporter. (d) Clopyralid alone also fails to activate Wnt reporter. 


\section{REFERENCES}

1. Satterstrom, F. K., Kosmicki, J. A., Wang, J., Breen, M. S., De Rubeis, S., An, J. Y., Peng, M., Collins, R., Grove, J., Klei, L., Stevens, C., Reichert, J., Mulhern, M. S., Artomov, M., Gerges, S., Sheppard, B., Xu, X., Bhaduri, A., Norman, U., Brand, H., Schwartz, G., Nguyen, R., Guerrero, E. E., Dias, C., Autism Sequencing, C., i, P.-B. C., Betancur, C., Cook, E. H., Gallagher, L., Gill, M., Sutcliffe, J. S., Thurm, A., Zwick, M. E., Borglum, A. D., State, M. W., Cicek, A. E., Talkowski, M. E., Cutler, D. J., Devlin, B., Sanders, S. J., Roeder, K., Daly, M. J., and Buxbaum, J. D. (2020) Large-Scale Exome Sequencing Study Implicates Both Developmental and Functional Changes in the Neurobiology of Autism. Cell 180, 568-584 e523

2. Feliciano, P., Zhou, X., Astrovskaya, I., Turner, T. N., Wang, T., Brueggeman, L., Barnard, R., Hsieh, A., Snyder, L. G., Muzny, D. M., Sabo, A., Consortium, S., Gibbs, R. A., Eichler, E. E., O'Roak, B. J., Michaelson, J. J., Volfovsky, N., Shen, Y., and Chung, W. K. (2019) Exome sequencing of 457 autism families recruited online provides evidence for autism risk genes. NPJ Genom Med 4, 19

3. Martin, P. M., Yang, X., Robin, N., Lam, E., Rabinowitz, J. S., Erdman, C. A., Quinn, J., Weiss, L. A., Hamilton, S. P., Kwok, P. Y., Moon, R. T., and Cheyette, B. N. (2013) A rare WNT1 missense variant overrepresented in ASD leads to increased Wnt signal pathway activation. Translational psychiatry $\mathbf{3}$, e301

4. Packer, A. (2018) Enrichment of factors regulating canonical Wnt signaling among autism risk genes. Molecular psychiatry 23, 492-493

5. Pinto, D., Delaby, E., Merico, D., Barbosa, M., Merikangas, A., Klei, L., Thiruvahindrapuram, B., Xu, X., Ziman, R., Wang, Z., Vorstman, J. A., Thompson, A., Regan, R., Pilorge, M., Pellecchia, G., Pagnamenta, A. T., Oliveira, B., Marshall, C. R., Magalhaes, T. R., Lowe, J. K., Howe, J. L., Griswold, A. J., Gilbert, J., Duketis, E., Dombroski, B. A., De Jonge, M. V., Cuccaro, M., Crawford, E. L., Correia, C. T., Conroy, J., Conceicao, I. C., Chiocchetti, A. G., Casey, J. P., Cai, G., Cabrol, C., Bolshakova, N., Bacchelli, E., Anney, R., Gallinger, S., Cotterchio, M., Casey, G., Zwaigenbaum, L., Wittemeyer, K., Wing, K., Wallace, S., van Engeland, H., Tryfon, A., Thomson, S., Soorya, L., Roge, B., Roberts, W., Poustka, F., Mouga, S., Minshew, N., McInnes, L. A., McGrew, S. G., Lord, C., Leboyer, M., Le Couteur, A. S., Kolevzon, A., Jimenez Gonzalez, P., Jacob, S., Holt, R., Guter, S., Green, J., Green, A., Gillberg, C., Fernandez, B. A., Duque, F., Delorme, R., Dawson, G., Chaste, P., Cafe, C., Brennan, S., Bourgeron, T., Bolton, P. F., Bolte, S., Bernier, R., Baird, G., Bailey, A. J., Anagnostou, E., Almeida, J., Wijsman, E. M., Vieland, V. J., Vicente, A. M., Schellenberg, G. D., Pericak-Vance, M., Paterson, A. D., Parr, J. R., Oliveira, G., Nurnberger, J. I., Monaco, A. P., Maestrini, E., Klauck, S. M., Hakonarson, H., Haines, J. L., Geschwind, D. H., Freitag, C. M., Folstein, S. E., Ennis, S., Coon, H., Battaglia, A., Szatmari, P., Sutcliffe, J. S., Hallmayer, J., Gill, M., Cook, E. H., Buxbaum, J. D., Devlin, B., Gallagher, L., Betancur, C., and Scherer, S. W. (2014) Convergence of genes and cellular pathways dysregulated in autism spectrum disorders. Am J Hum Genet 94, 677-694

6. de la Torre-Ubieta, L., Won, H., Stein, J. L., and Geschwind, D. H. (2016) Advancing the understanding of autism disease mechanisms through genetics. Nature medicine 22, 345-361

7. Kwan, V., Unda, B. K., and Singh, K. K. (2016) Wnt signaling networks in autism spectrum disorder and intellectual disability. Journal of neurodevelopmental disorders $\mathbf{8 , 4 5}$

8. Marchetto, M. C., Belinson, H., Tian, Y., Freitas, B. C., Fu, C., Vadodaria, K. C., Beltrao-Braga, P. C., Trujillo, C. A., Mendes, A. P., Padmanabhan, K., Nunez, Y., Ou, J., Ghosh, H., Wright, R., Brennand, K. J., Pierce, K., Eichenfield, L., Pramparo, T., Eyler, L. T., Barnes, C. C., Courchesne, E., Geschwind, D. H., Gage, F. H., Wynshaw-Boris, A., and Muotri, A. R. (2016) Altered proliferation and networks in neural cells derived from idiopathic autistic individuals. Molecular psychiatry 
9. Y Yi, J. J., Paranjape, S. R., Walker, M. P., Choudhury, R., Wolter, J. M., Fragola, G., Emanuele, M. J., Major, M. B., and Zylka, M. J. (2017) The autism-linked UBE3A T485A mutant E3 ubiquitin ligase activates the Wnt/beta-catenin pathway by inhibiting the proteasome. The Journal of biological chemistry 292, 12503-12515

10. Mulligan, K. A., and Cheyette, B. N. (2012) Wnt signaling in vertebrate neural development and function. Journal of neuroimmune pharmacology : the official journal of the Society on NeuroImmune Pharmacology 7, 774-787

11. Noelanders, R., and Vleminckx, K. (2017) How Wnt Signaling Builds the Brain: Bridging Development and Disease. The Neuroscientist : a review journal bringing neurobiology, neurology and psychiatry 23, 314-329

12. Chenn, A., and Walsh, C. A. (2002) Regulation of cerebral cortical size by control of cell cycle exit in neural precursors. Science 297, 365-369

13. Gaugler, T., Klei, L., Sanders, S. J., Bodea, C. A., Goldberg, A. P., Lee, A. B., Mahajan, M., Manaa, D., Pawitan, Y., Reichert, J., Ripke, S., Sandin, S., Sklar, P., Svantesson, O., Reichenberg, A., Hultman, C. M., Devlin, B., Roeder, K., and Buxbaum, J. D. (2014) Most genetic risk for autism resides with common variation. Nat Genet 46, 881-885

14. Modabbernia, A., Velthorst, E., and Reichenberg, A. (2017) Environmental risk factors for autism: an evidence-based review of systematic reviews and meta-analyses. Molecular autism 8, 13

15. Shelton, J. F., Geraghty, E. M., Tancredi, D. J., Delwiche, L. D., Schmidt, R. J., Ritz, B., Hansen, R. L., and Hertz-Picciotto, I. (2014) Neurodevelopmental disorders and prenatal residential proximity to agricultural pesticides: the CHARGE study. Environmental health perspectives 122, 1103-1109

16. Roberts, E. M., English, P. B., Grether, J. K., Windham, G. C., Somberg, L., and Wolff, C. (2007) Maternal residence near agricultural pesticide applications and autism spectrum disorders among children in the California Central Valley. Environmental health perspectives 115, 1482-1489

17. Pearson, B. L., Simon, J. M., McCoy, E. S., Salazar, G., Fragola, G., and Zylka, M. J. (2016) Identification of chemicals that mimic transcriptional changes associated with autism, brain aging and neurodegeneration. Nature communications 7, 11173

18. Simon, J. M., Paranjape, S. R., Wolter, J. M., Salazar, G., and Zylka, M. J. (2019) High-throughput screening and classification of chemicals and their effects on neuronal gene expression using RASL-seq. Scientific reports $\mathbf{9}, 4529$

19. Thomas, R. H. (2018) Valproate: life-saving, life-changing. Clin Med (Lond) 18, s1-s8

20. Meador, K., Reynolds, M. W., Crean, S., Fahrbach, K., and Probst, C. (2008) Pregnancy outcomes in women with epilepsy: a systematic review and meta-analysis of published pregnancy registries and cohorts. Epilepsy research $\mathbf{8 1}, 1-13$

21. Williams, G., King, J., Cunningham, M., Stephan, M., Kerr, B., and Hersh, J. H. (2001) Fetal valproate syndrome and autism: additional evidence of an association. Developmental medicine and child neurology 43, 202-206

22. Christensen, J., Gronborg, T. K., Sorensen, M. J., Schendel, D., Parner, E. T., Pedersen, L. H., and Vestergaard, M. (2013) Prenatal valproate exposure and risk of autism spectrum disorders and childhood autism. JAMA : the journal of the American Medical Association 309, 1696-1703

23. Go, H. S., Kim, K. C., Choi, C. S., Jeon, S. J., Kwon, K. J., Han, S. H., Lee, J., Cheong, J. H., Ryu, J. H., Kim, C. H., Ko, K. H., and Shin, C. Y. (2012) Prenatal exposure to valproic acid increases the neural progenitor cell pool and induces macrocephaly in rat brain via a mechanism involving the GSK3beta/beta-catenin pathway. Neuropharmacology 63, 1028-1041 
24. Sabers, A., Bertelsen, F. C., Scheel-Kruger, J., Nyengaard, J. R., and Moller, A. (2014) Long-term valproic acid exposure increases the number of neocortical neurons in the developing rat brain. A possible new animal model of autism. Neuroscience letters 580, 12-16

25. Phiel, C. J., Zhang, F., Huang, E. Y., Guenther, M. G., Lazar, M. A., and Klein, P. S. (2001) Histone deacetylase is a direct target of valproic acid, a potent anticonvulsant, mood stabilizer, and teratogen. The Journal of biological chemistry 276, 36734-36741

26. Alimohamad, H., Sutton, L., Mouyal, J., Rajakumar, N., and Rushlow, W. J. (2005) The effects of antipsychotics on beta-catenin, glycogen synthase kinase-3 and dishevelled in the ventral midbrain of rats. Journal of neurochemistry 95, 513-525

27. Pan, B., Huang, X. F., and Deng, C. (2016) Chronic administration of aripiprazole activates GSK3betadependent signalling pathways, and up-regulates GABAA receptor expression and CREB1 activity in rats. Scientific reports 6, 30040

28. Dix, D. J., Houck, K. A., Martin, M. T., Richard, A. M., Setzer, R. W., and Kavlock, R. J. (2007) The ToxCast program for prioritizing toxicity testing of environmental chemicals. Toxicological sciences : an official journal of the Society of Toxicology 95, 5-12

29. Thomas, R. S., Paules, R. S., Simeonov, A., Fitzpatrick, S. C., Crofton, K. M., Casey, W. M., and Mendrick, D. L. (2018) The US Federal Tox21 Program: A strategic and operational plan for continued leadership. ALTEX 35, 163-168

30. Major, M. B., Camp, N. D., Berndt, J. D., Yi, X., Goldenberg, S. J., Hubbert, C., Biechele, T. L., Gingras, A. C., Zheng, N., Maccoss, M. J., Angers, S., and Moon, R. T. (2007) Wilms tumor suppressor WTX negatively regulates WNT/beta-catenin signaling. Science 316, 1043-1046

31. Yi, J. J., Berrios, J., Newbern, J. M., Snider, W. D., Philpot, B. D., Hahn, K. M., and Zylka, M. J. (2015) An Autism-Linked Mutation Disables Phosphorylation Control of UBE3A. Cell 162, 795-807

32. Yi, J. J., Paranjape, S. R., Walker, M. P., Choudhury, R., Wolter, J. M., Fragola, G., Emanuele, M. J., Major, M. B., and Zylka, M. J. (2017) The autism-linked UBE3A T485A mutant E3 ubiquitin ligase activates the Wnt/beta-catenin pathway by inhibiting the proteasome. The Journal of biological chemistry

33. Dull, T., Zufferey, R., Kelly, M., Mandel, R. J., Nguyen, M., Trono, D., and Naldini, L. (1998) A thirdgeneration lentivirus vector with a conditional packaging system. Journal of virology 72, 8463-8471

34. Backman, T. W., Cao, Y., and Girke, T. (2011) ChemMine tools: an online service for analyzing and clustering small molecules. Nucleic acids research 39, W486-491

35. Wambaugh, J. F., Wang, A., Dionisio, K. L., Frame, A., Egeghy, P., Judson, R., and Setzer, R. W. (2014) High throughput heuristics for prioritizing human exposure to environmental chemicals. Environ Sci Technol 48, 12760-12767

36. Stein, J. L., de la Torre-Ubieta, L., Tian, Y., Parikshak, N. N., Hernandez, I. A., Marchetto, M. C., Baker, D. K., Lu, D., Hinman, C. R., Lowe, J. K., Wexler, E. M., Muotri, A. R., Gage, F. H., Kosik, K. S., and Geschwind, D. H. (2014) A quantitative framework to evaluate modeling of cortical development by neural stem cells. Neuron 83, 69-86

37. Wolter, J. M., Mao, H., Fragola, G., Simon, J. M., Krantz, J. L., Bazick, H. O., Oztemiz, B., Stein, J. L., and Zylka, M. J. (2020) Cas9 gene therapy for Angelman syndrome traps Ube3a-ATS long non-coding RNA. Nature 587, 281-284

38. Richard, A. M., Judson, R. S., Houck, K. A., Grulke, C. M., Volarath, P., Thillainadarajah, I., Yang, C., Rathman, J., Martin, M. T., Wambaugh, J. F., Knudsen, T. B., Kancherla, J., Mansouri, K., Patlewicz, G., Williams, A. J., Little, S. B., Crofton, K. M., and Thomas, R. S. (2016) ToxCast Chemical Landscape: Paving the Road to 21st Century Toxicology. Chemical research in toxicology 29, 1225 1251 
39. Cohen, P., and Goedert, M. (2004) GSK3 inhibitors: development and therapeutic potential. Nature reviews. Drug discovery 3, 479-487

40. Klein, P. S., and Melton, D. A. (1996) A molecular mechanism for the effect of lithium on development. Proceedings of the National Academy of Sciences of the United States of America 93, 8455-8459

41. Zhang, J. H., Chung, T. D., and Oldenburg, K. R. (1999) A Simple Statistical Parameter for Use in Evaluation and Validation of High Throughput Screening Assays. Journal of biomolecular screening 4, $67-73$

42. Stathopoulos, G. P., Dimitroulis, J., Antoniou, D., Katis, C., Tsavdaridis, D., Armenaki, O., Marosis, C., Michalopoulou, P., Grigoratou, T., and Stathopoulos, J. (2005) Front-line paclitaxel and irinotecan combination chemotherapy in advanced non-small-cell lung cancer: a phase I-II trial. British journal of cancer 93, 1106-1111

43. Allen-Mersh, T. G., Earlam, S., Fordy, C., Abrams, K., and Houghton, J. (1994) Quality of life and survival with continuous hepatic-artery floxuridine infusion for colorectal liver metastases. Lancet 344, 1255-1260

44. Lin, H. D., Hsu, L. S., Chien, C. C., and Chen, S. C. (2018) Proteomic analysis of ametryn toxicity in zebrafish embryos. Environmental toxicology 33, 579-586

45. Santos, T., Cancian, G., Neodini, D. N., Mano, D. R., Capucho, C., Predes, F. S., Barbieri, R., Oliveira, C. A., Pigoso, A. A., Dolder, H., and Severi-Aguiar, G. D. (2015) Toxicological evaluation of ametryn effects in Wistar rats. Experimental and toxicologic pathology : official journal of the Gesellschaft fur Toxikologische Pathologie 67, 525-532

46. Charli, A., Jin, H., Anantharam, V., Kanthasamy, A., and Kanthasamy, A. G. (2016) Alterations in mitochondrial dynamics induced by tebufenpyrad and pyridaben in a dopaminergic neuronal cell culture model. Neurotoxicology 53, 302-313

47. van der Stel, W., Carta, G., Eakins, J., Darici, S., Delp, J., Forsby, A., Bennekou, S. H., Gardner, I., Leist, M., Danen, E. H. J., Walker, P., van de Water, B., and Jennings, P. (2020) Multiparametric assessment of mitochondrial respiratory inhibition in HepG2 and RPTEC/TERT1 cells using a panel of mitochondrial targeting agrochemicals. Archives of toxicology 94, 2707-2729

48. Priyadarshi, A., Khuder, S. A., Schaub, E. A., and Shrivastava, S. (2000) A meta-analysis of Parkinson's disease and exposure to pesticides. Neurotoxicology 21, 435-440

49. Sherer, T. B., Richardson, J. R., Testa, C. M., Seo, B. B., Panov, A. V., Yagi, T., Matsuno-Yagi, A., Miller, G. W., and Greenamyre, J. T. (2007) Mechanism of toxicity of pesticides acting at complex I: relevance to environmental etiologies of Parkinson's disease. Journal of neurochemistry 100, 1469-1479

50. Xu, X., Sepich, C., Lukas, R. J., Zhu, G., and Chang, Y. (2016) Emamectin is a non-selective allosteric activator of nicotinic acetylcholine receptors and GABAA/C receptors. Biochemical and biophysical research communications $\mathbf{4 7 3}, 795-800$

51. Yen, T. H., and Lin, J. L. (2004) Acute poisoning with emamectin benzoate. J Toxicol Clin Toxicol 42 , 657-661

52. Bakovic, M., Fullerton, M. D., and Michel, V. (2007) Metabolic and molecular aspects of ethanolamine phospholipid biosynthesis: the role of CTP:phosphoethanolamine cytidylyltransferase (Pcyt2).

Biochemistry and cell biology = Biochimie et biologie cellulaire 85, 283-300

53. Vance, J. E., and Tasseva, G. (2013) Formation and function of phosphatidylserine and phosphatidylethanolamine in mammalian cells. Biochimica et biophysica acta 1831, 543-554

54. Tuladhar, R., Yarravarapu, N., Ma, Y., Zhang, C., Herbert, J., Kim, J., Chen, C., and Lum, L. (2019) Stereoselective fatty acylation is essential for the release of lipidated WNT proteins from the acyltransferase Porcupine (PORCN). The Journal of biological chemistry 294, 6273-6282 
55. Nile, A. H., and Hannoush, R. N. (2016) Fatty acylation of Wnt proteins. Nature chemical biology 12 , 60-69

56. Kalgutkar, A. S., Hatch, H. L., Kosea, F., Nguyen, H. T., Choo, E. F., McClure, K. F., Taylor, T. J., Henne, K. R., Kuperman, A. V., Dombroski, M. A., and Letavic, M. A. (2006) Preclinical pharmacokinetics and metabolism of 6-(4-(2,5-difluorophenyl)oxazol-5-yl)-3-isopropyl-[1,2,4]triazolo[4,3-a]pyridine, a novel and selective p38alpha inhibitor: identification of an active metabolite in preclinical species and human liver microsomes. Biopharmaceutics \& drug disposition 27, 371-386

57. Bikkavilli, R. K., Feigin, M. E., and Malbon, C. C. (2008) p38 mitogen-activated protein kinase regulates canonical Wnt-beta-catenin signaling by inactivation of GSK3beta. Journal of cell science 121, 3598-3607

58. Hou, X., Tan, Y., Li, M., Dey, S. K., and Das, S. K. (2004) Canonical Wnt signaling is critical to estrogen-mediated uterine growth. Mol Endocrinol 18, 3035-3049

59. Shi, B., Liang, J., Yang, X., Wang, Y., Zhao, Y., Wu, H., Sun, L., Zhang, Y., Chen, Y., Li, R., Zhang, Y., Hong, M., and Shang, Y. (2007) Integration of estrogen and Wnt signaling circuits by the polycomb group protein EZH2 in breast cancer cells. Molecular and cellular biology 27, 5105-5119

60. Skah, S., Uchuya-Castillo, J., Sirakov, M., and Plateroti, M. (2017) The thyroid hormone nuclear receptors and the Wnt/beta-catenin pathway: An intriguing liaison. Dev Biol 422, 71-82

61. Zhou, H., Mak, W., Kalak, R., Street, J., Fong-Yee, C., Zheng, Y., Dunstan, C. R., and Seibel, M. J. (2009) Glucocorticoid-dependent Wnt signaling by mature osteoblasts is a key regulator of cranial skeletal development in mice. Development 136, 427-436

62. Ohnaka, K., Tanabe, M., Kawate, H., Nawata, H., and Takayanagi, R. (2005) Glucocorticoid suppresses the canonical Wnt signal in cultured human osteoblasts. Biochemical and biophysical research communications 329, 177-181

63. Crinnion, W. J. (2010) The CDC fourth national report on human exposure to environmental chemicals: what it tells us about our toxic burden and how it assist environmental medicine physicians. Altern Med Rev 15, 101-109

64. (TPMC), T. P. a. M. C. (2002) Report on Carcinogens Background Document for Diethanolamine. NIEHS, National Toxicology Program N01ES85421

65. Fiume, M. M., Heldreth, B., Bergfeld, W. F., Belsito, D. V., Hill, R. A., Klaassen, C. D., Liebler, D. C., Marks, J. G., Jr., Shank, R. C., Slaga, T. J., Snyder, P. W., and Andersen, F. A. (2017) Safety Assessment of Diethanolamine and Its Salts as Used in Cosmetics. International journal of toxicology 36, 89S-110S

66. Council, T. P. C. P. (2010) International Cosmetic Ingredient Dictionary and Handbook

67. Grosse, Y., Baan, R., Secretan-Lauby, B., El Ghissassi, F., Bouvard, V., Benbrahim-Tallaa, L., Guha, N., Islami, F., Galichet, L., Straif, K., and Group, W. H. O. I. A. f. R. o. C. M. W. (2011) Carcinogenicity of chemicals in industrial and consumer products, food contaminants and flavourings, and water chlorination byproducts. The lancet oncology 12, 328-329

68. National Toxicology, P. (1999) NTP Toxicology and Carcinogenesis Studies of Oleic Acid Diethanolamine Condensate (CAS No. 93-83-4) in F344/N Rats and B6C3F1 Mice (Dermal Studies). Natl Toxicol Program Tech Rep Ser 481, 1-198

69. Mathews, J. M., Garner, C. E., and Matthews, H. B. (1995) Metabolism, bioaccumulation, and incorporation of diethanolamine into phospholipids. Chemical research in toxicology 8, 625-633

70. Niculescu, M. D., Wu, R., Guo, Z., da Costa, K. A., and Zeisel, S. H. (2007) Diethanolamine alters proliferation and choline metabolism in mouse neural precursor cells. Toxicological sciences : an official journal of the Society of Toxicology 96, 321-326 
71. Craciunescu, C. N., Wu, R., and Zeisel, S. H. (2006) Diethanolamine alters neurogenesis and induces apoptosis in fetal mouse hippocampus. The FASEB journal : official publication of the Federation of American Societies for Experimental Biology 20, 1635-1640

72. Craciunescu, C. N., Niculescu, M. D., Guo, Z., Johnson, A. R., Fischer, L., and Zeisel, S. H. (2009) Dose response effects of dermally applied diethanolamine on neurogenesis in fetal mouse hippocampus and potential exposure of humans. Toxicological sciences : an official journal of the Society of Toxicology 107, 220-226

73. Lehman-McKeeman, L. D., Gamsky, E. A., Hicks, S. M., Vassallo, J. D., Mar, M. H., and Zeisel, S. H. (2002) Diethanolamine induces hepatic choline deficiency in mice. Toxicological sciences : an official journal of the Society of Toxicology 67, 38-45

74. Guo, X., and Wang, X. F. (2009) Signaling cross-talk between TGF-beta/BMP and other pathways. Cell research 19, 71-88

75. Williams, A. J., Grulke, C. M., Edwards, J., McEachran, A. D., Mansouri, K., Baker, N. C., Patlewicz, G., Shah, I., Wambaugh, J. F., Judson, R. S., and Richard, A. M. (2017) The CompTox Chemistry Dashboard: a community data resource for environmental chemistry. Journal of cheminformatics $\mathbf{9}, 61$

76. Hayashi, S. M., Ton, T. V., Hong, H. H., Irwin, R. D., Haseman, J. K., Devereux, T. R., and Sills, R. C. (2003) Genetic alterations in the Catnb gene but not the H-ras gene in hepatocellular neoplasms and hepatoblastomas of $\mathrm{B} 6 \mathrm{C} 3 \mathrm{~F}(1)$ mice following exposure to diethanolamine for 2 years. Chemicobiological interactions 146, 251-261

77. Sanders, L. M., and Zeisel, S. H. (2007) Choline: Dietary Requirements and Role in Brain Development. Nutr Today 42, 181-186

78. Bachman, A. N., Kamendulis, L. M., and Goodman, J. I. (2006) Diethanolamine and phenobarbital produce an altered pattern of methylation in GC-rich regions of DNA in B6C3F1 mouse hepatocytes similar to that resulting from choline deficiency. Toxicological sciences : an official journal of the Society of Toxicology 90, 317-325

79. van Meer, G., Voelker, D. R., and Feigenson, G. W. (2008) Membrane lipids: where they are and how they behave. Nature reviews. Molecular cell biology 9, 112-124

80. Hosseini, V., Dani, C., Geranmayeh, M. H., Mohammadzadeh, F., Nazari Soltan Ahmad, S., and Darabi, M. (2019) Wnt lipidation: Roles in trafficking, modulation, and function. Journal of cellular physiology 234, 8040-8054

81. Wang, L., Chai, Y., Li, C., Liu, H., Su, W., Liu, X., Yu, B., Lei, W., Yu, B., Crane, J. L., Cao, X., and Wan, M. (2018) Oxidized phospholipids are ligands for LRP6. Bone Res 6, 22

82. Oginuma, M., Harima, Y., Tarazona, O. A., Diaz-Cuadros, M., Michaut, A., Ishitani, T., Xiong, F., and Pourquie, O. (2020) Intracellular pH controls WNT downstream of glycolysis in amniote embryos. Nature 584, 98-101

83. Melnik, S., Dvornikov, D., Muller-Decker, K., Depner, S., Stannek, P., Meister, M., Warth, A., Thomas, M., Muley, T., Risch, A., Plass, C., Klingmuller, U., Niehrs, C., and Glinka, A. (2018) Cancer cell specific inhibition of Wnt/beta-catenin signaling by forced intracellular acidification. Cell Discov 4, 37

84. Condon, K. H., Ho, J., Robinson, C. G., Hanus, C., and Ehlers, M. D. (2013) The Angelman syndrome protein Ube3a/E6AP is required for Golgi acidification and surface protein sialylation. The Journal of neuroscience : the official journal of the Society for Neuroscience 33, 3799-3814

85. Commission", E. (2001) CosIng Database . Annex II. List of substances which must not form part of the composition of cosmetic products. Secondary alkyl- and alkanolamines and their salts, including diethanolamine.

86. Canada, H. (2019) Cosmetic Ingredient Hotlist. 
a

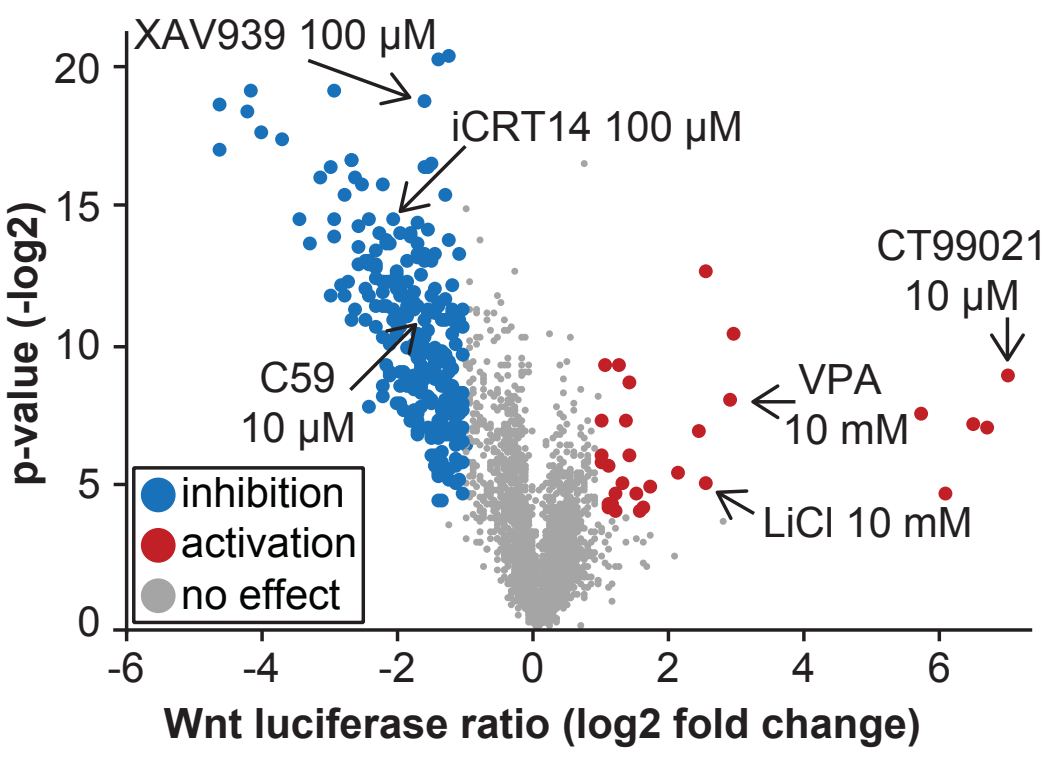

C

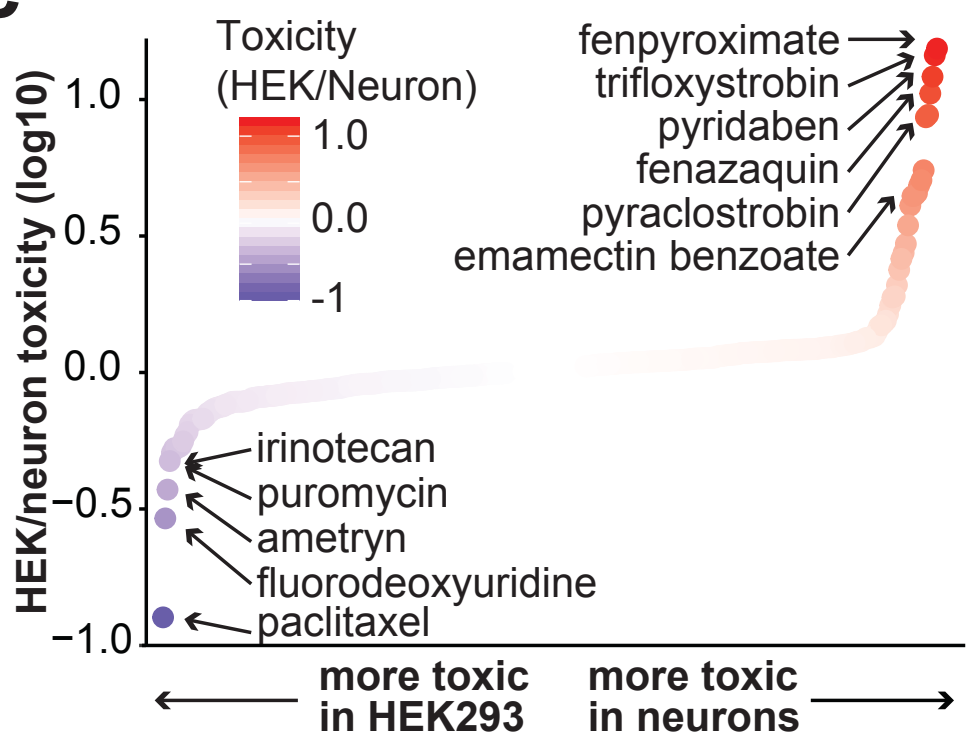

b

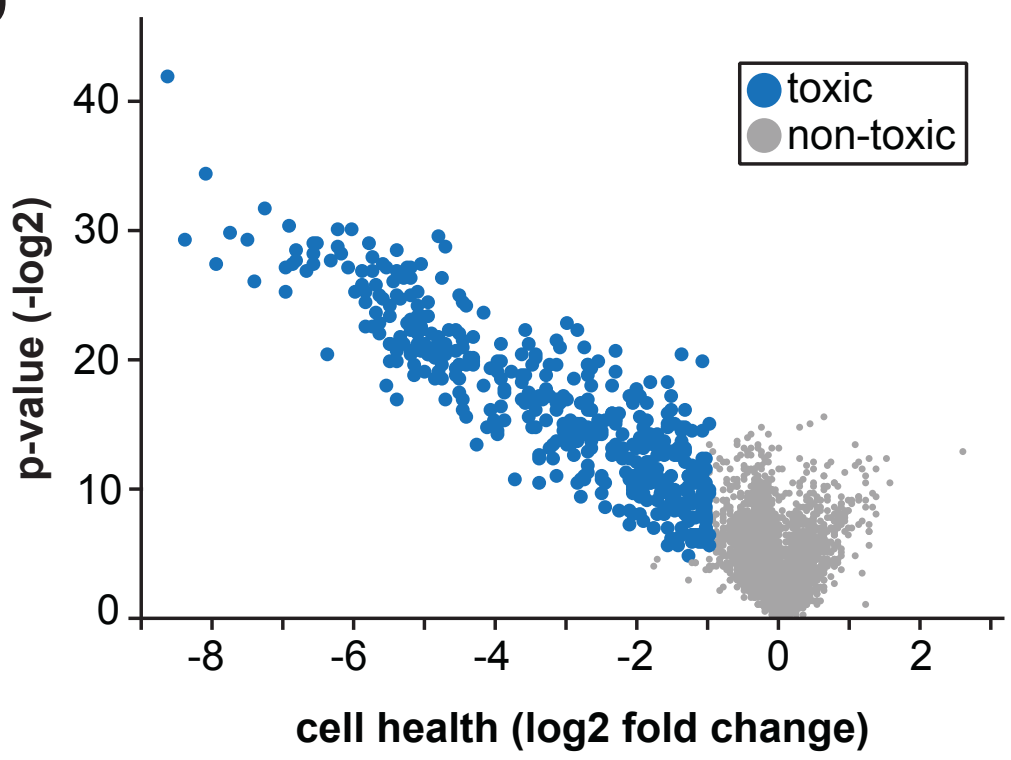

d

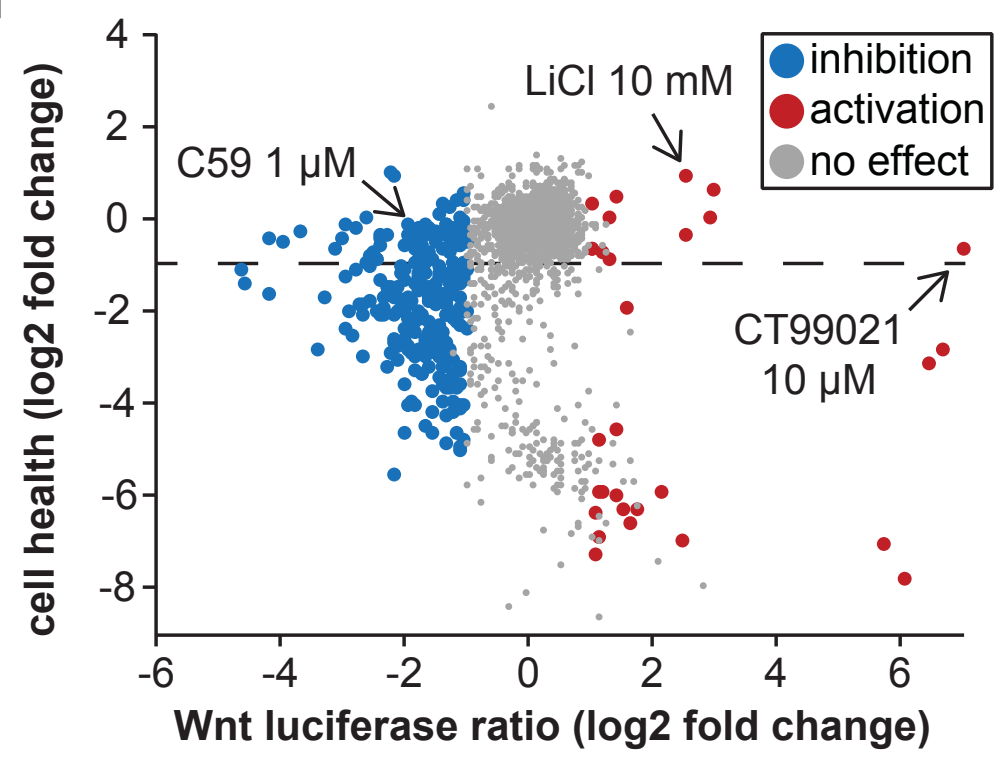




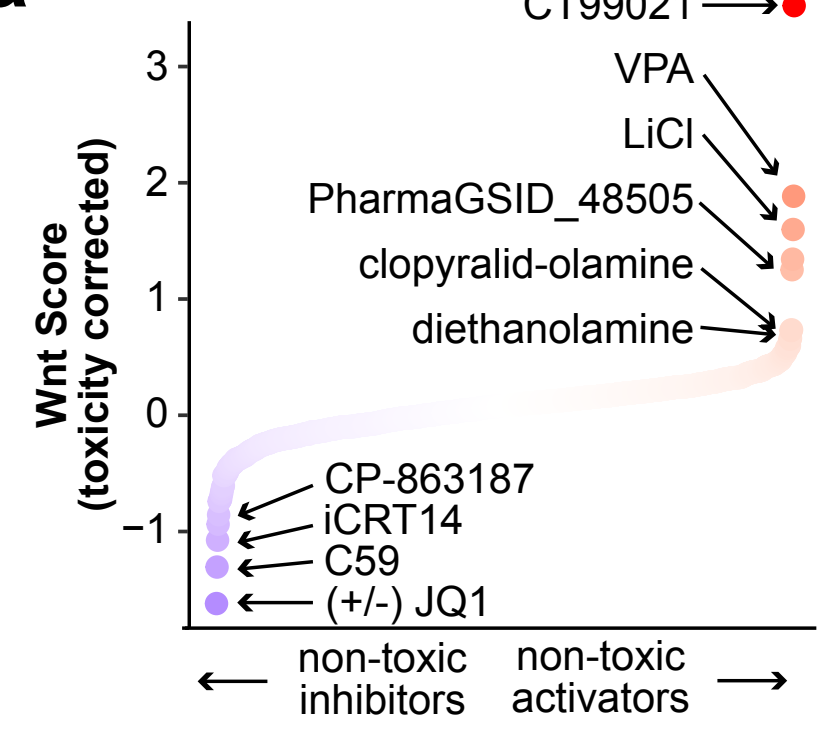

b

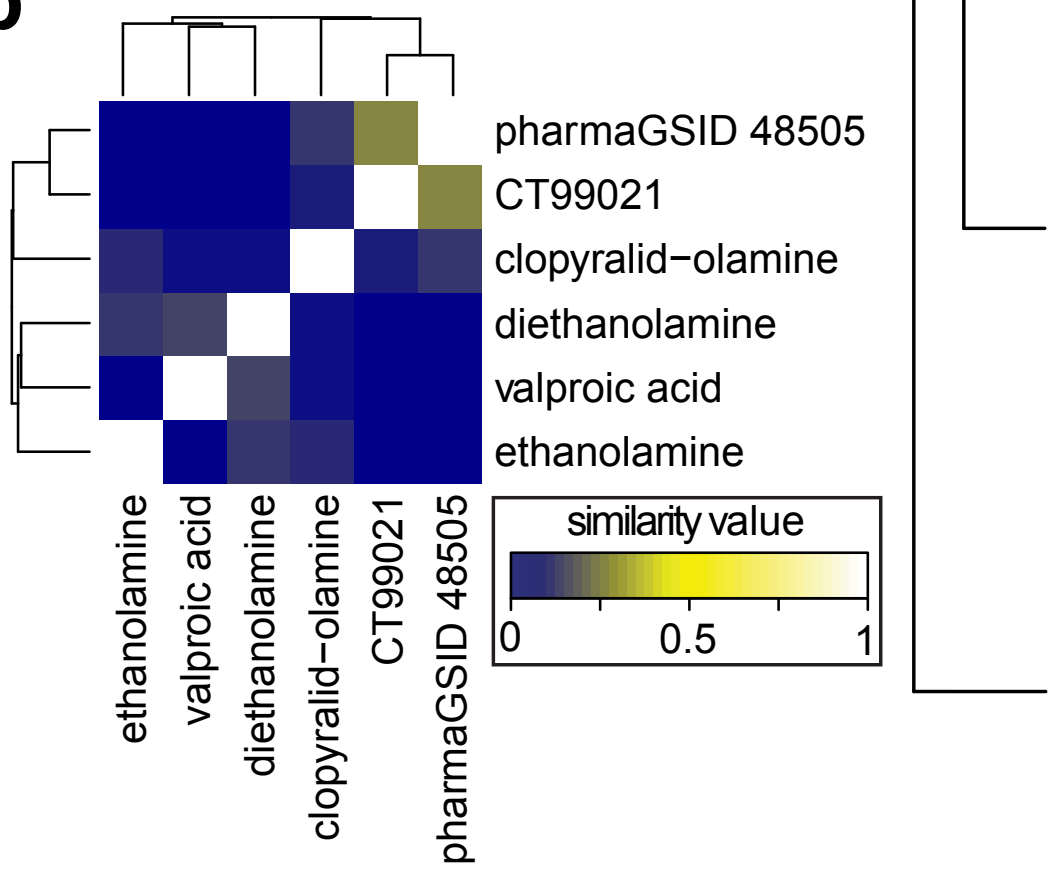<smiles>CCCC(CCC)C(=O)O</smiles>

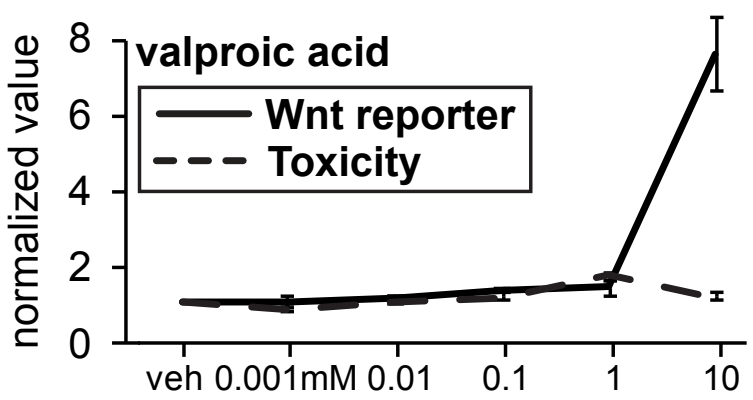<smiles>OCCNCCO</smiles>

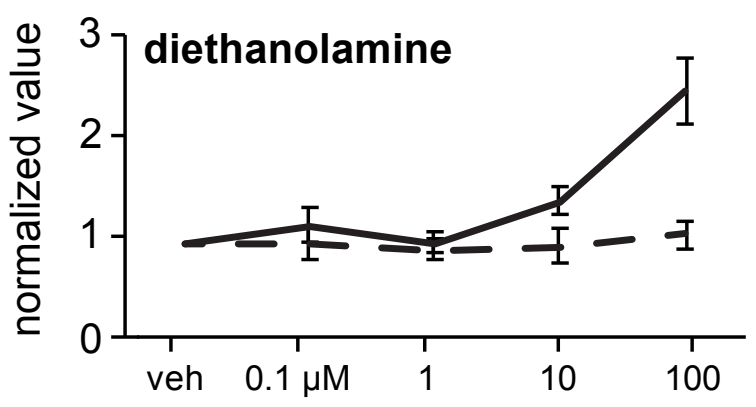

$\mathrm{HO} \curvearrowright \mathrm{NH}_{2}$

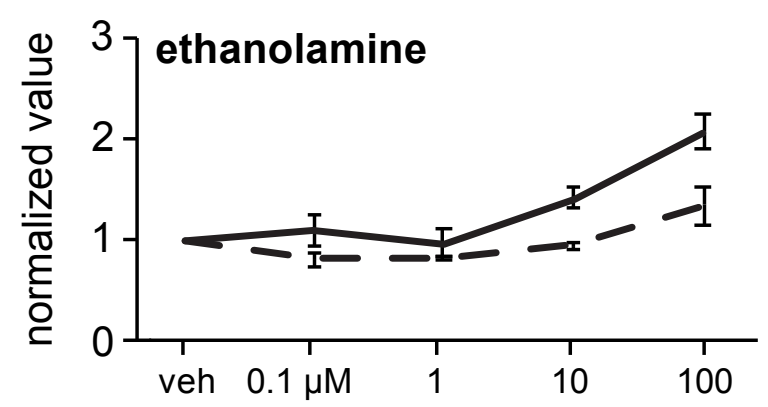

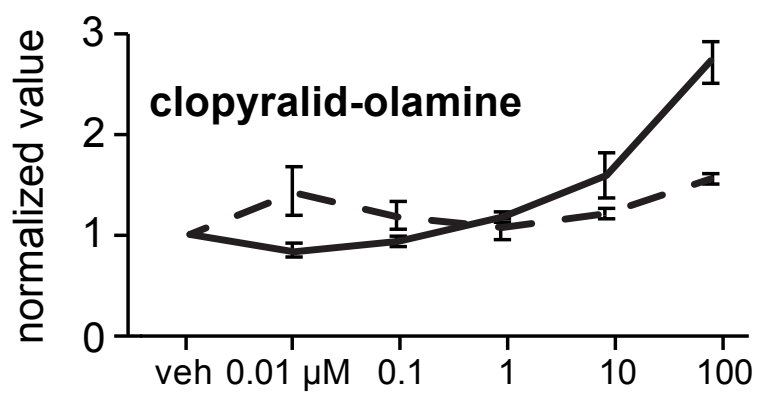


a
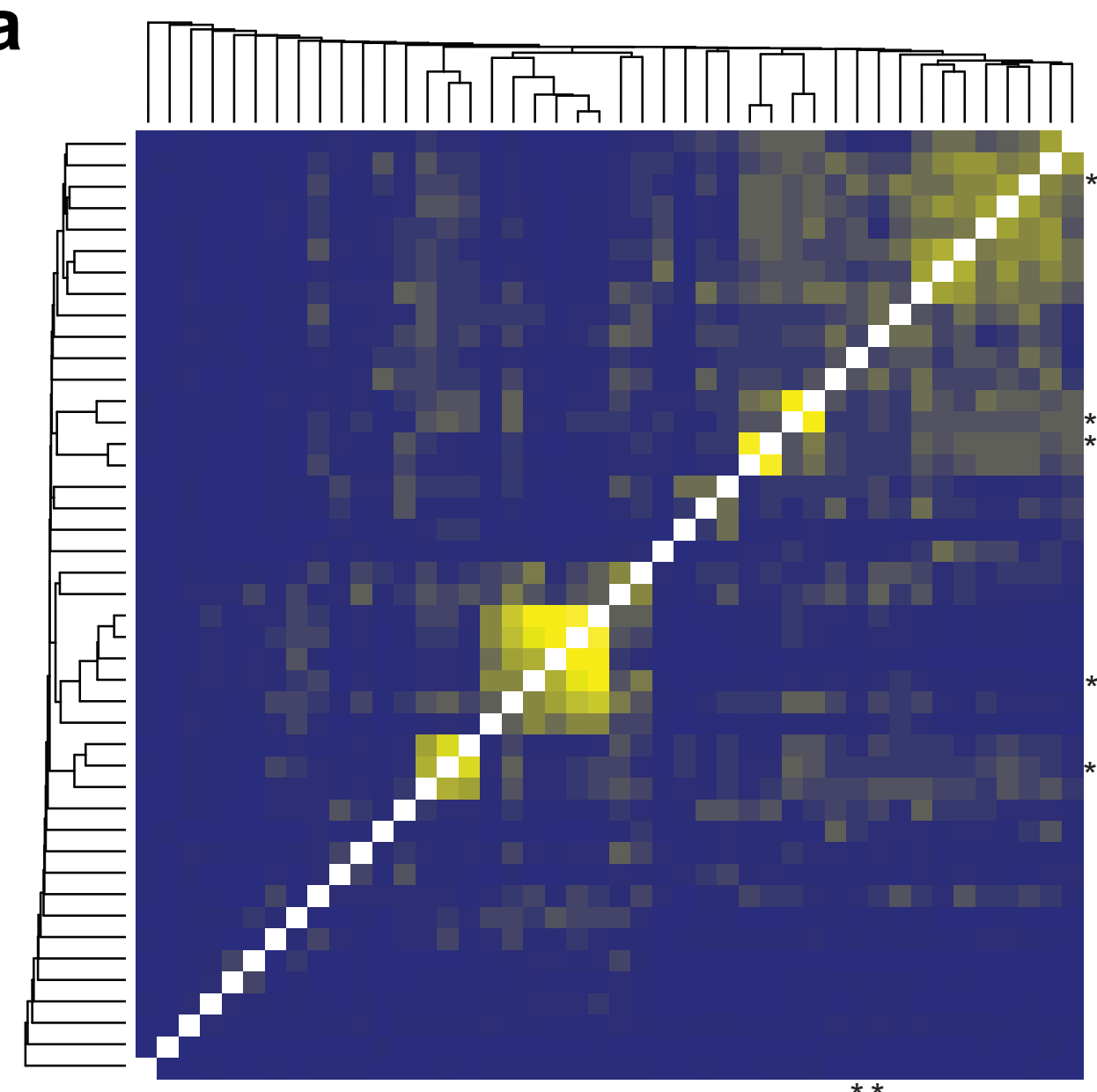

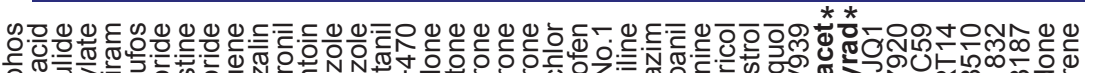

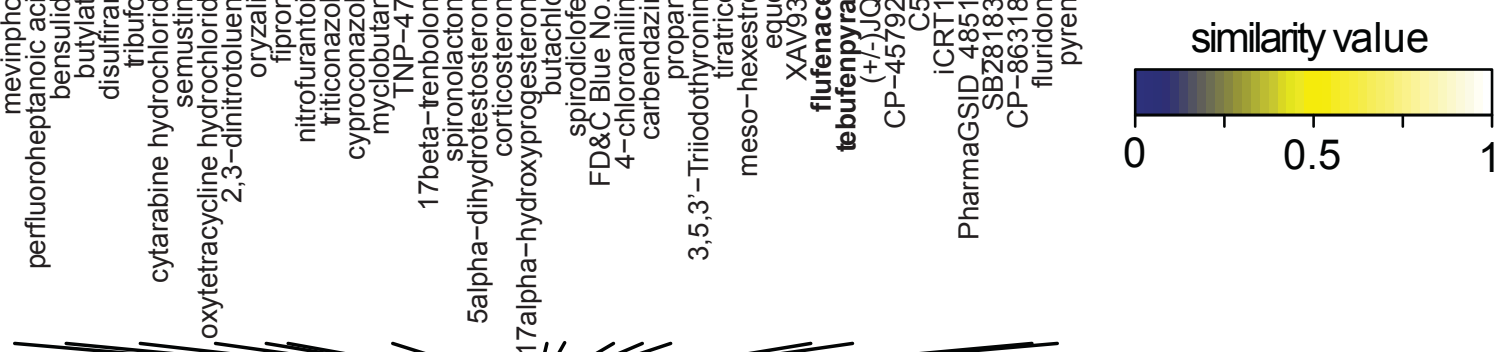

b

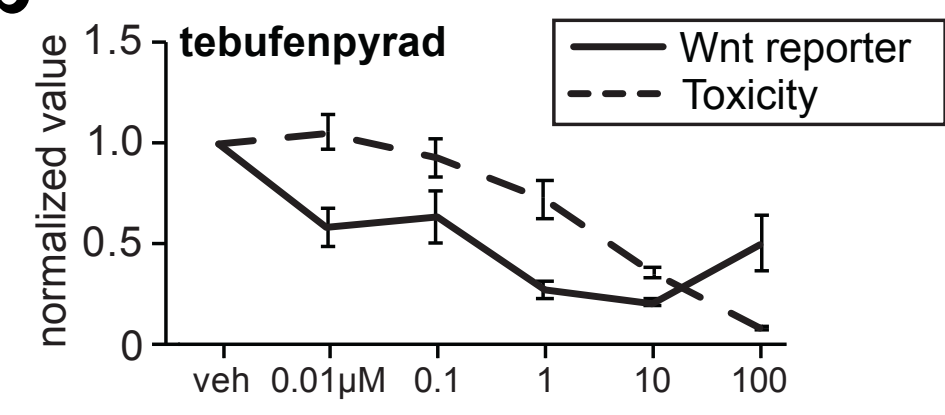

CRT14

CP-457920

tebufenpyrad

flufenacet

propanil

carbendazim

4-chloroaniline
FD\&C Blue No.1

spirodiclofen

17alpha-hydroxyprogesteron

5alpha-dihydrotestosterone

spironolactone

17beta-trenbolone

myclobutanil

nitrofurantoin

eronil

2,3-dinitrotoluene

oxytetracycline hydrochloride

cytarabine hydrochloride

tribufos

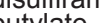

bensulide

perfluoroheptanoic_acid

mevinphos

C $\left.\begin{array}{l}\text { pyrene } \\ \text { fluridone } \\ \text { CP-863187 } \\ \text { SB281832 } \\ \text { pharmaGSID 48510 }\end{array}\right]$ p38 inhibitors (d)

equol

tiratricol $3,3^{\prime}-$ Triiodothyronine $]$ thyroid hormone

agricultural fungicides (h)

analogues (f)

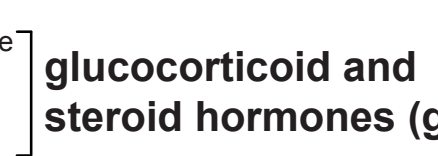
steroid hormones (g)

e
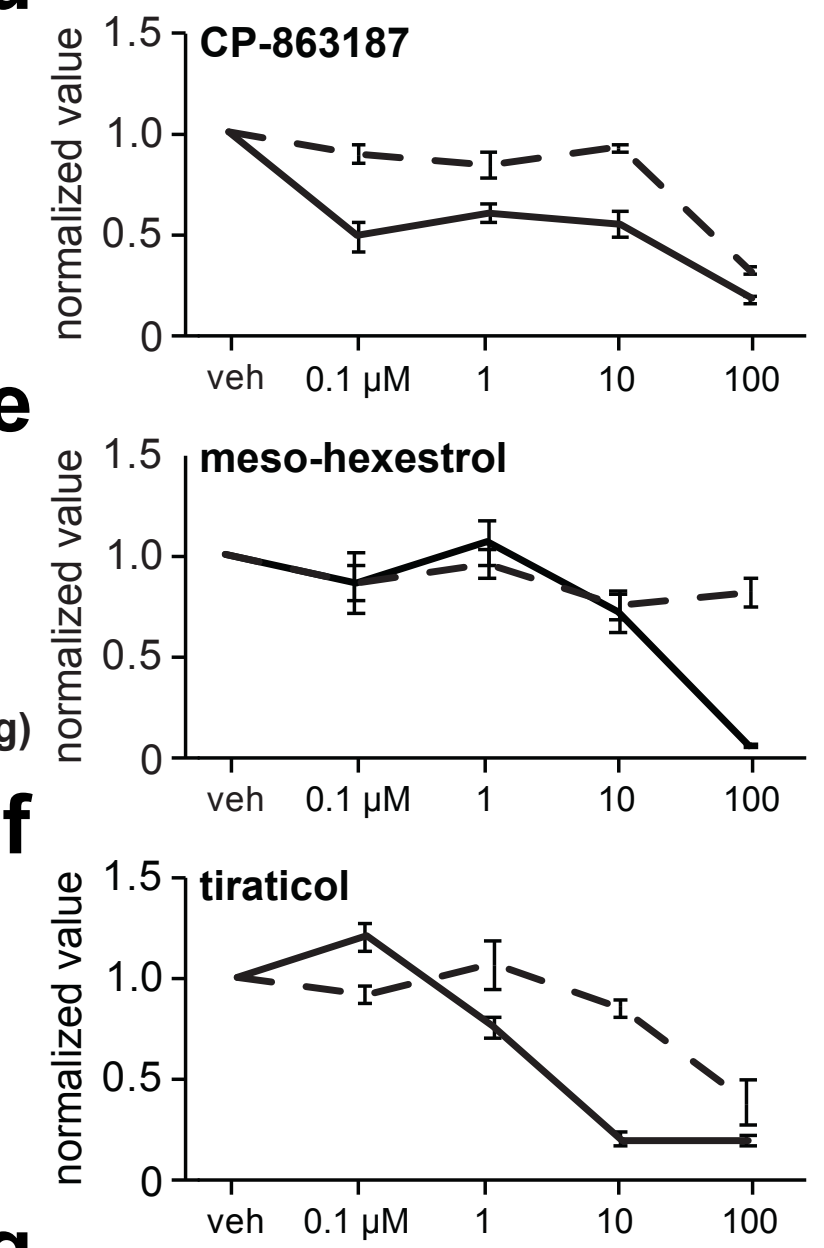

g
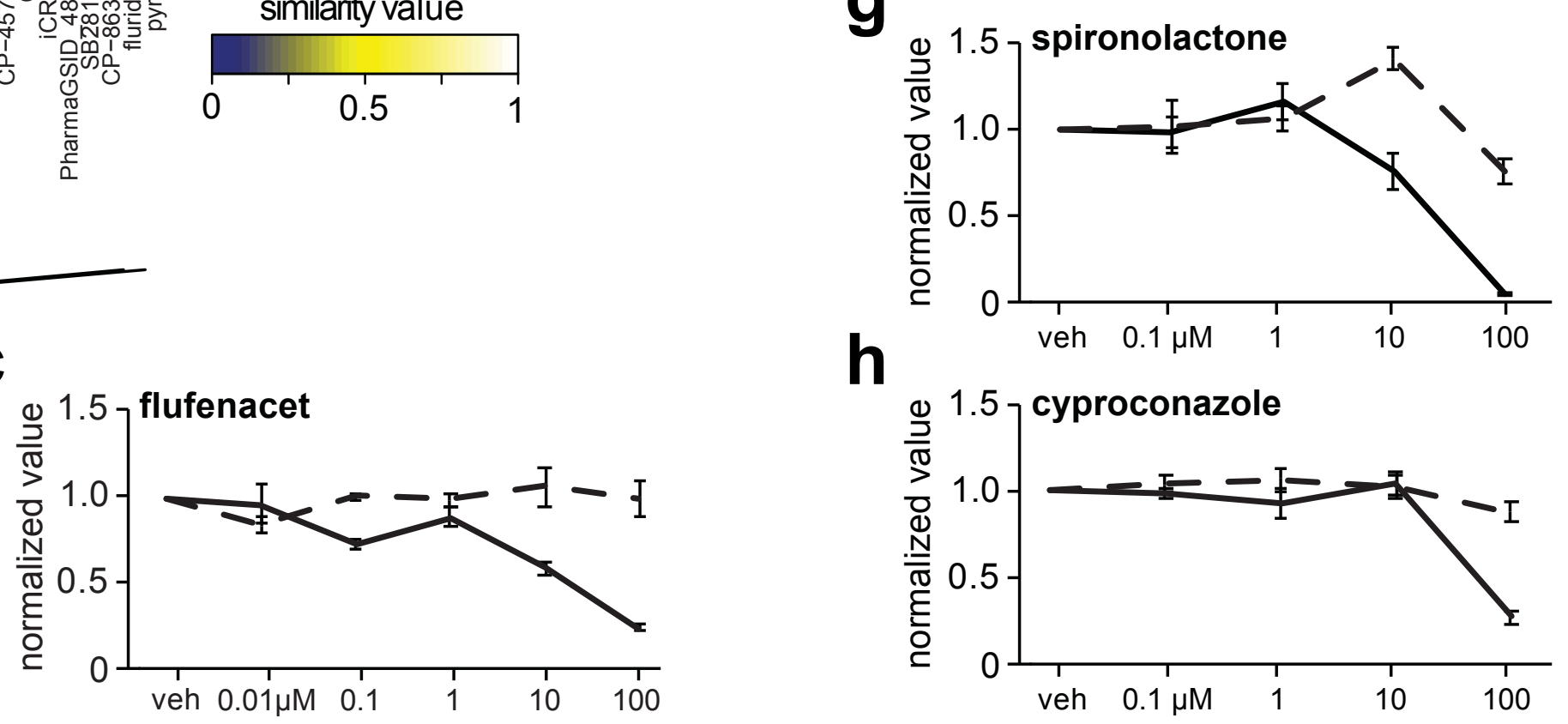


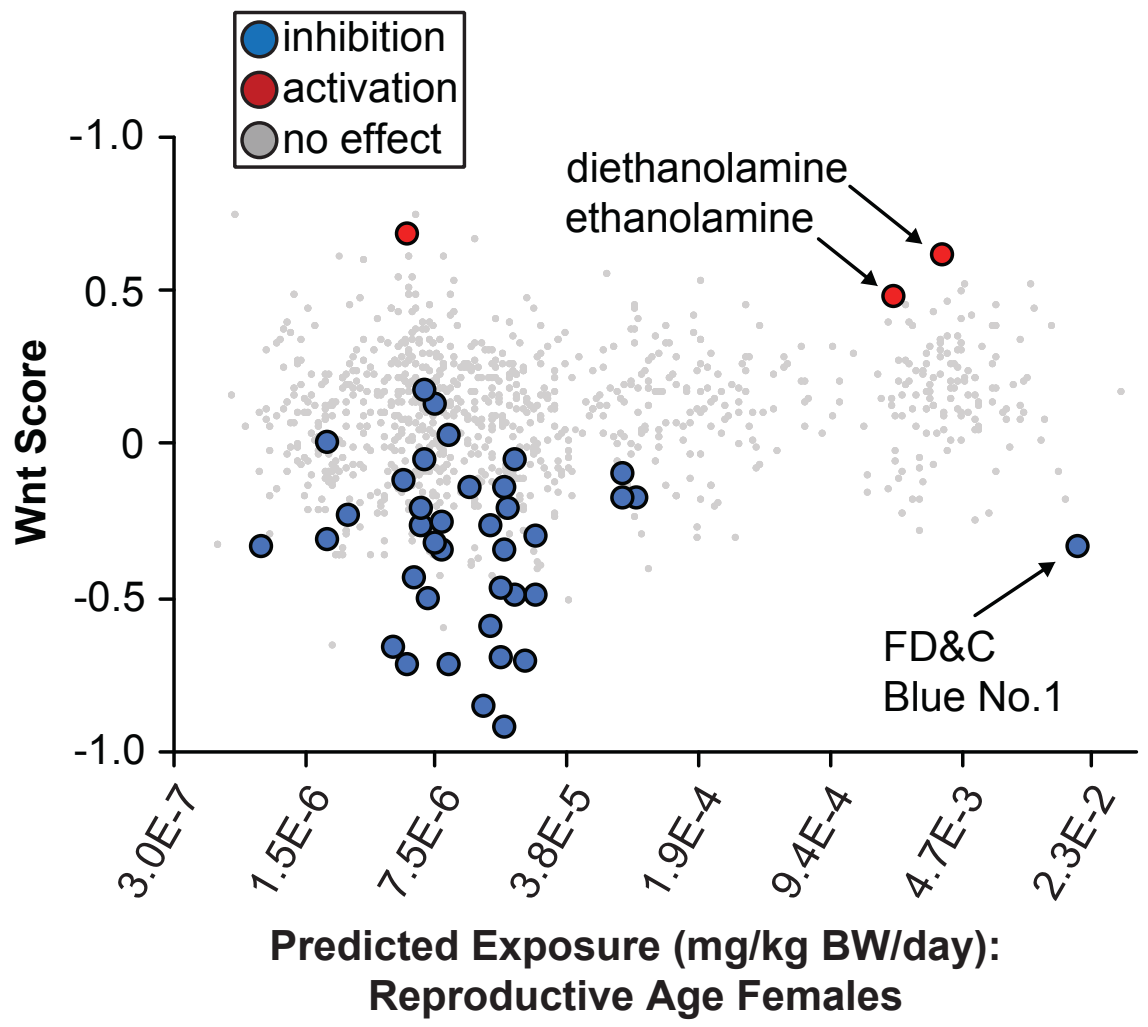


a

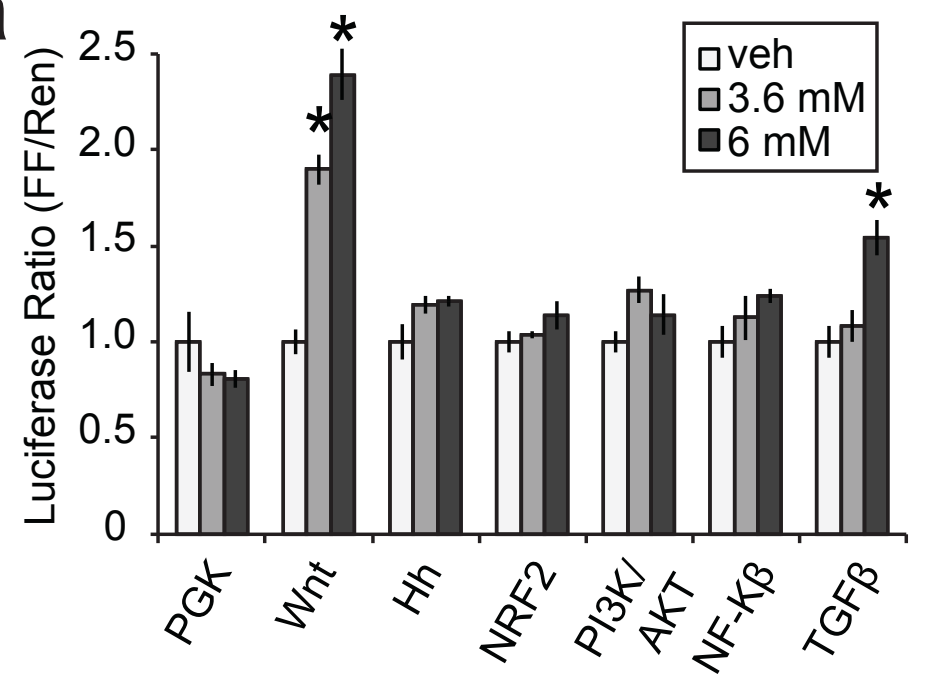

b

C

donor \#93

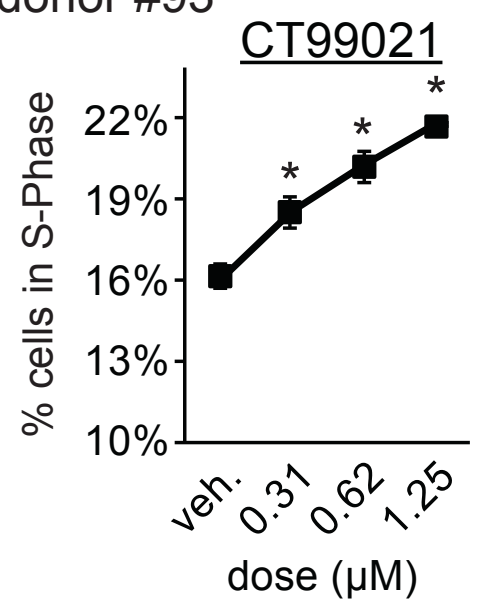

donor \#56
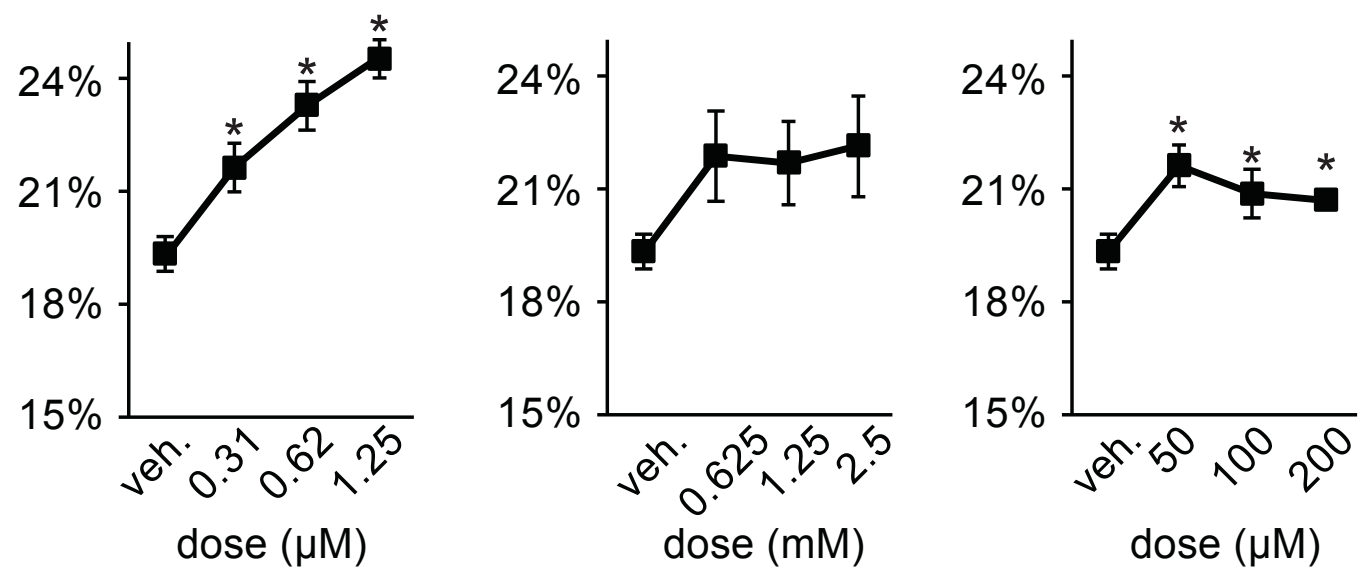
a

b

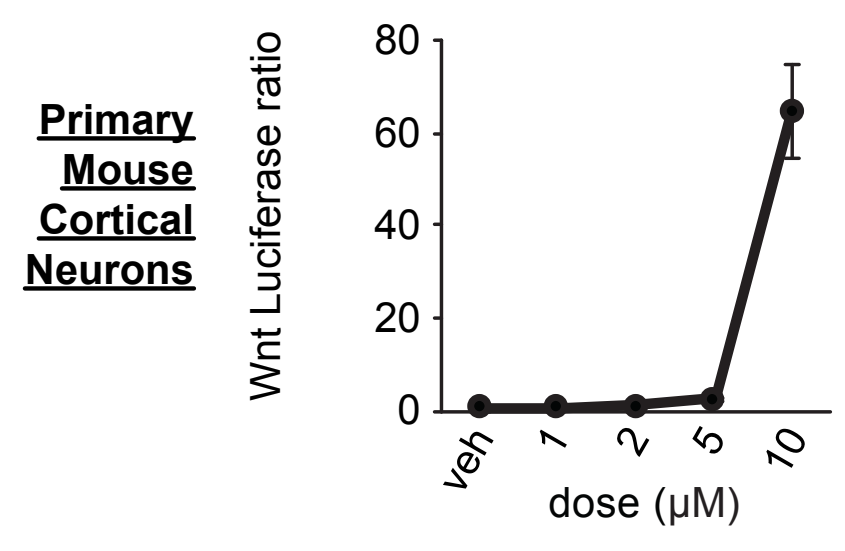

C
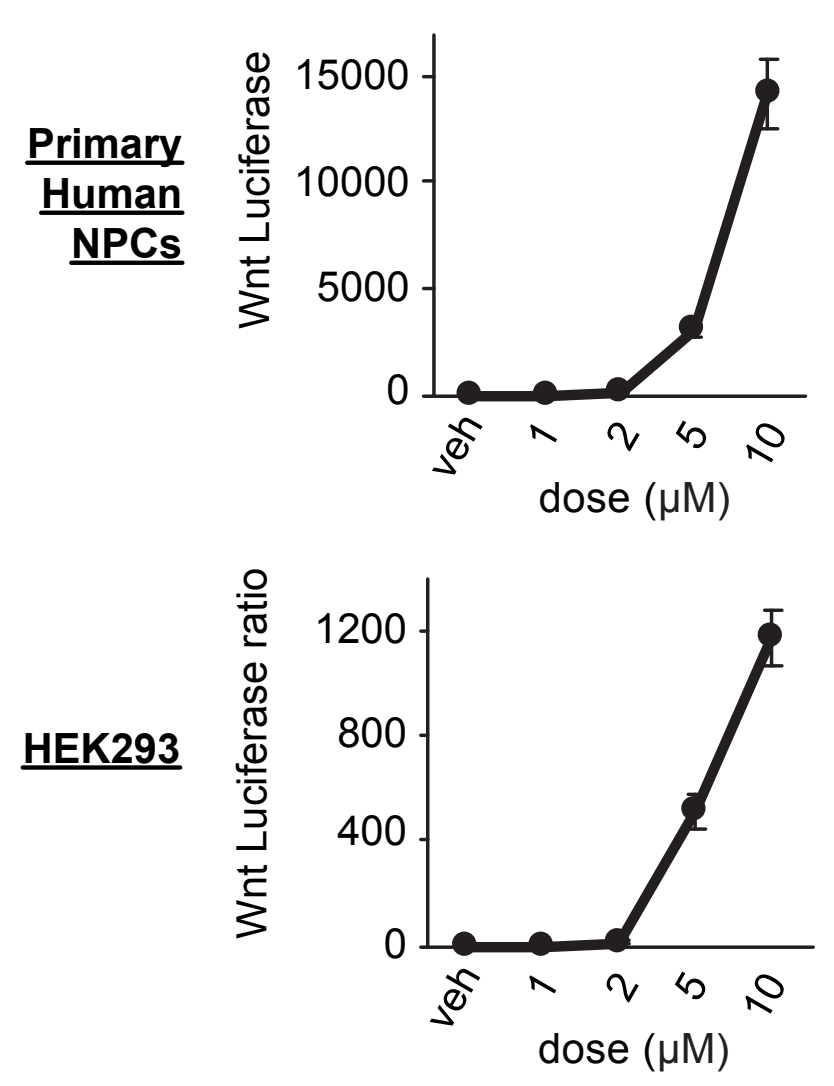

$\underline{\mathrm{LiCl}}$
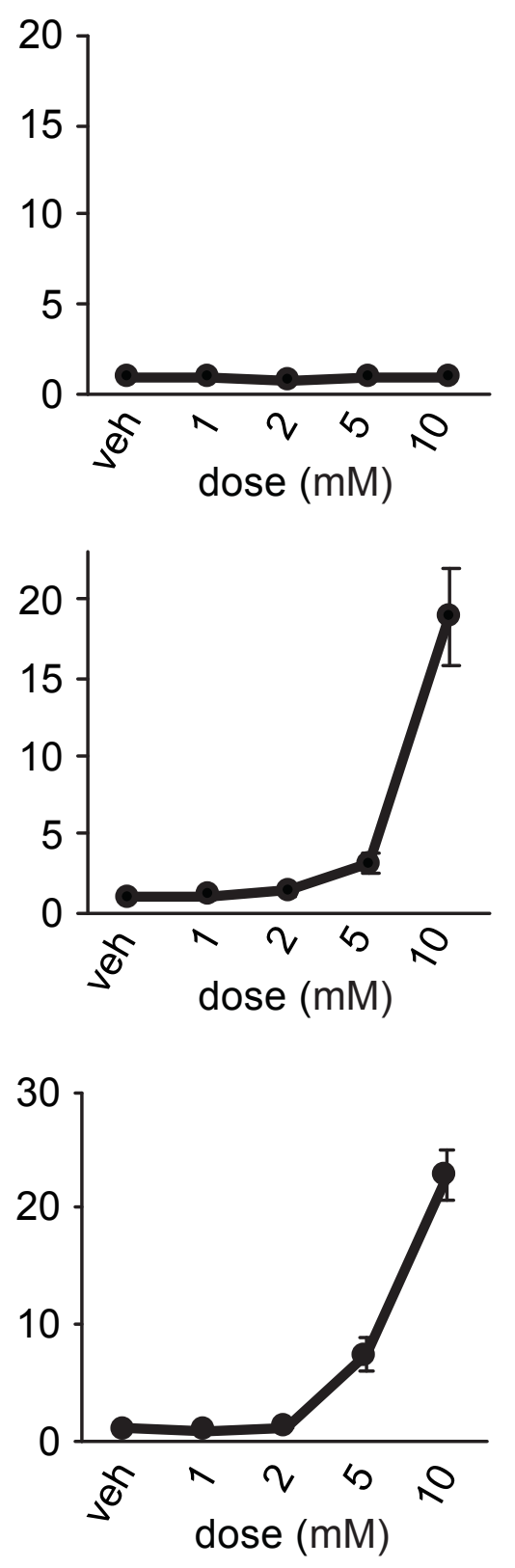

VPA
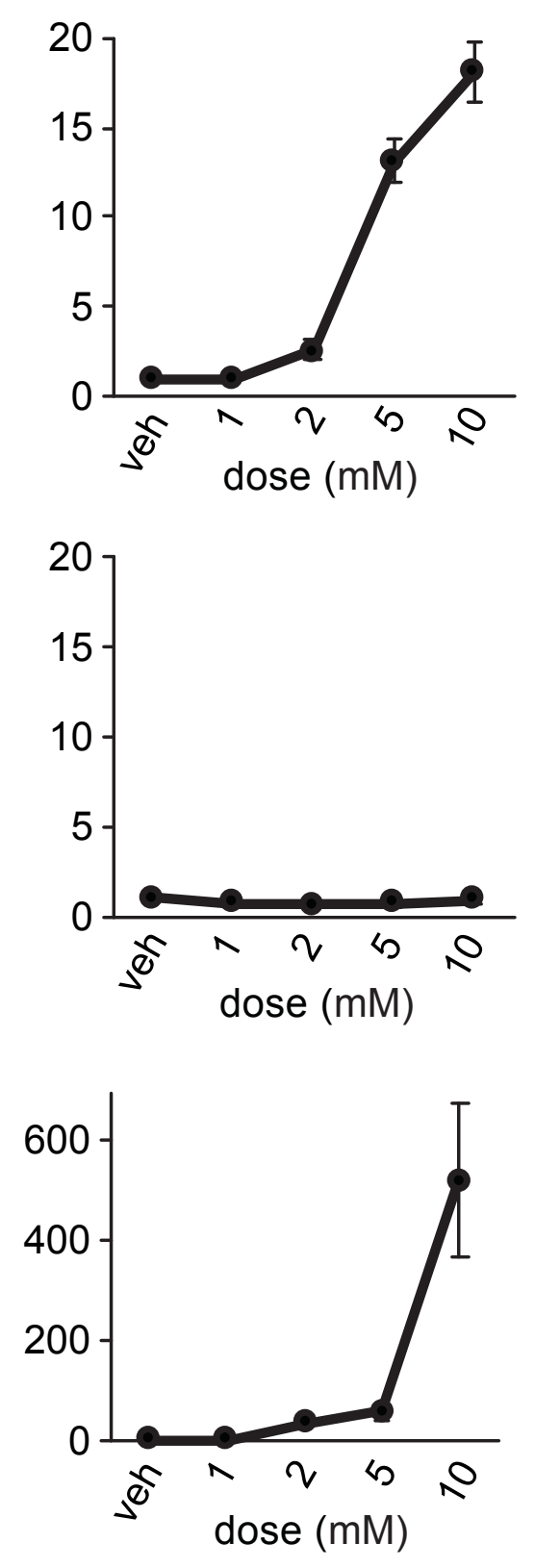

d

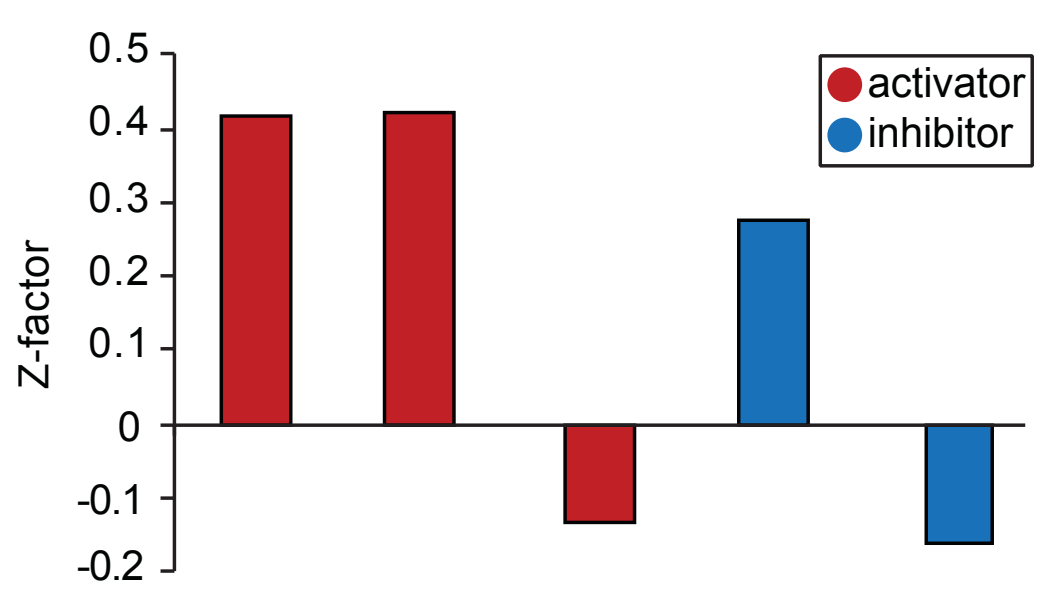

LiCl CT99021 VPA iCRT14 XAV939 $10 \mathrm{mM} \quad 10 \mu \mathrm{M} \quad 10 \mathrm{mM} \quad 100 \mathrm{uM} \quad 100 \mu \mathrm{M}$ 
a

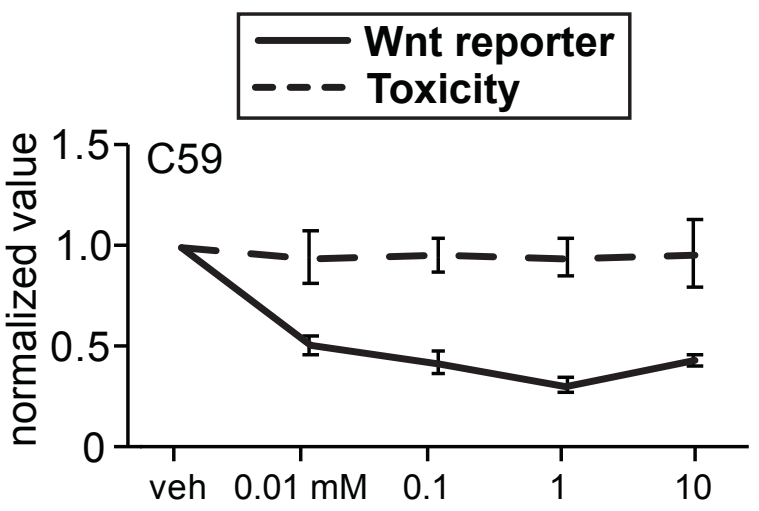

b

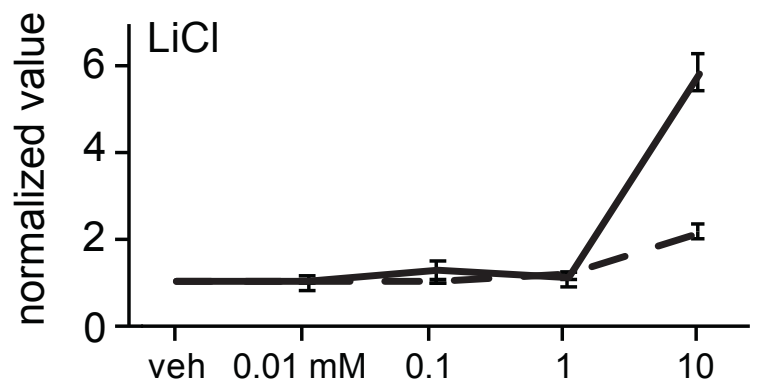

C

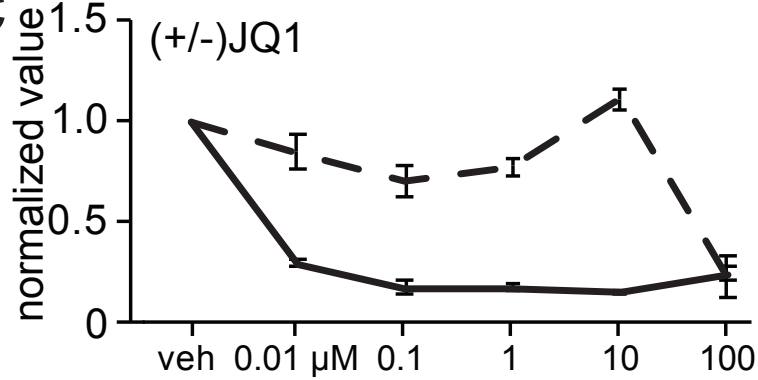

d

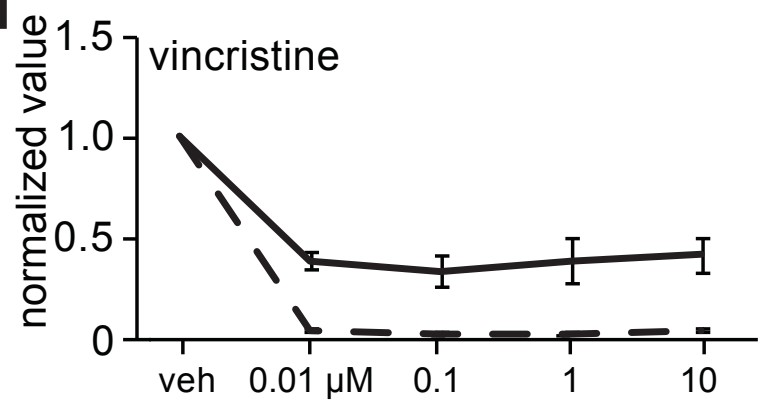

e

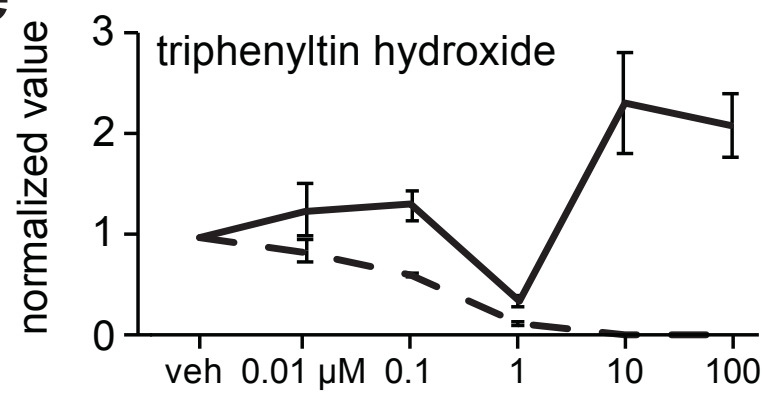

Toxicity

Corrected

Wnt Score

$-1.31$

1.60

$-1.62$

0.03

0.19 
a
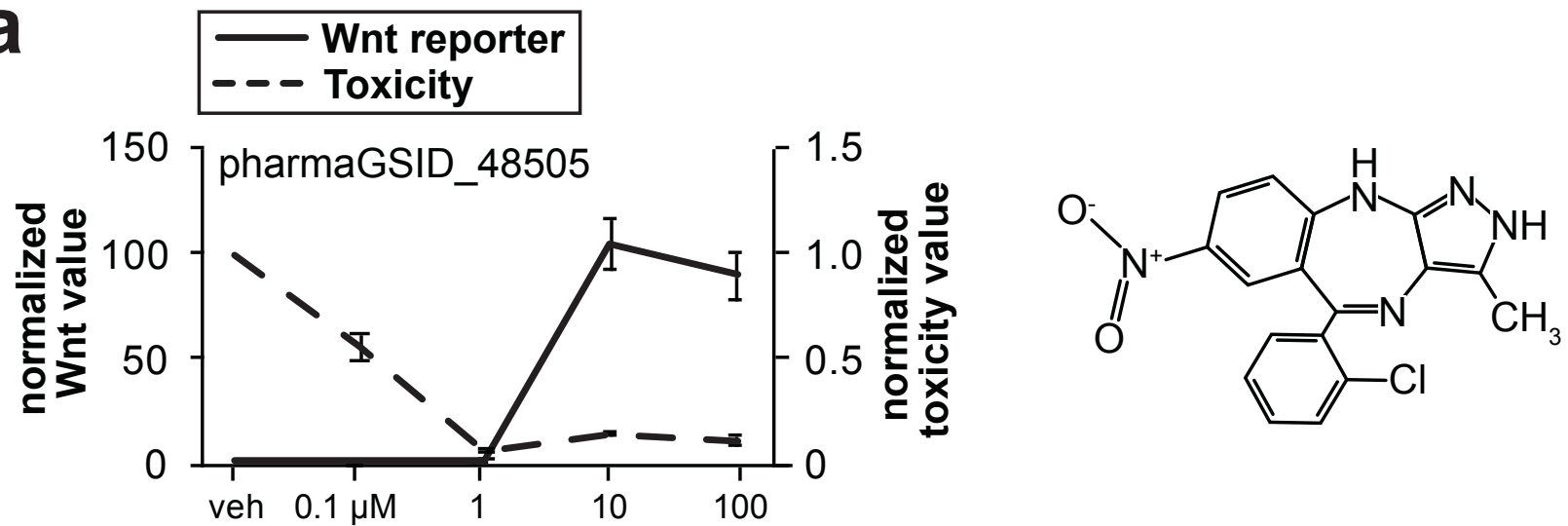

b $\quad 150$ ст99021

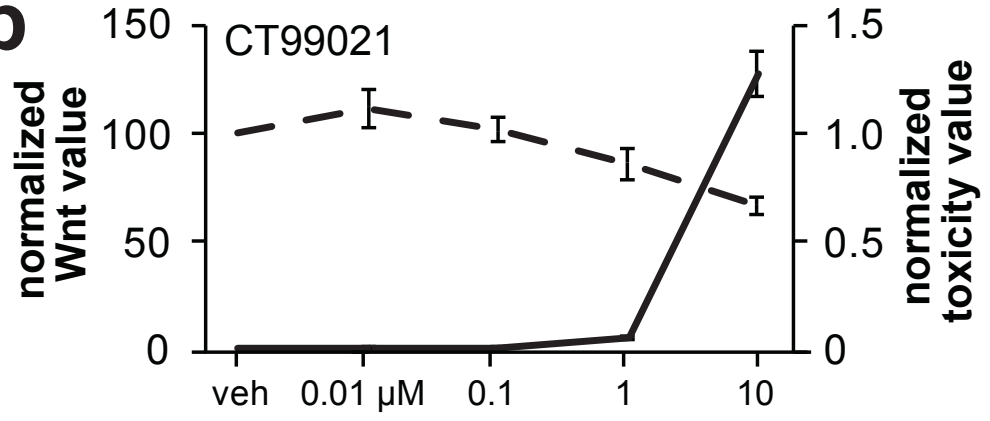

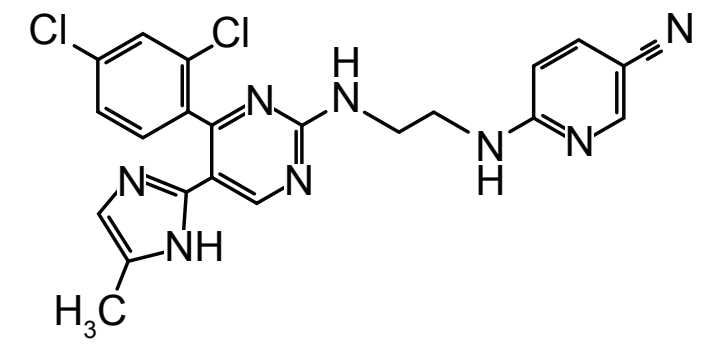

c
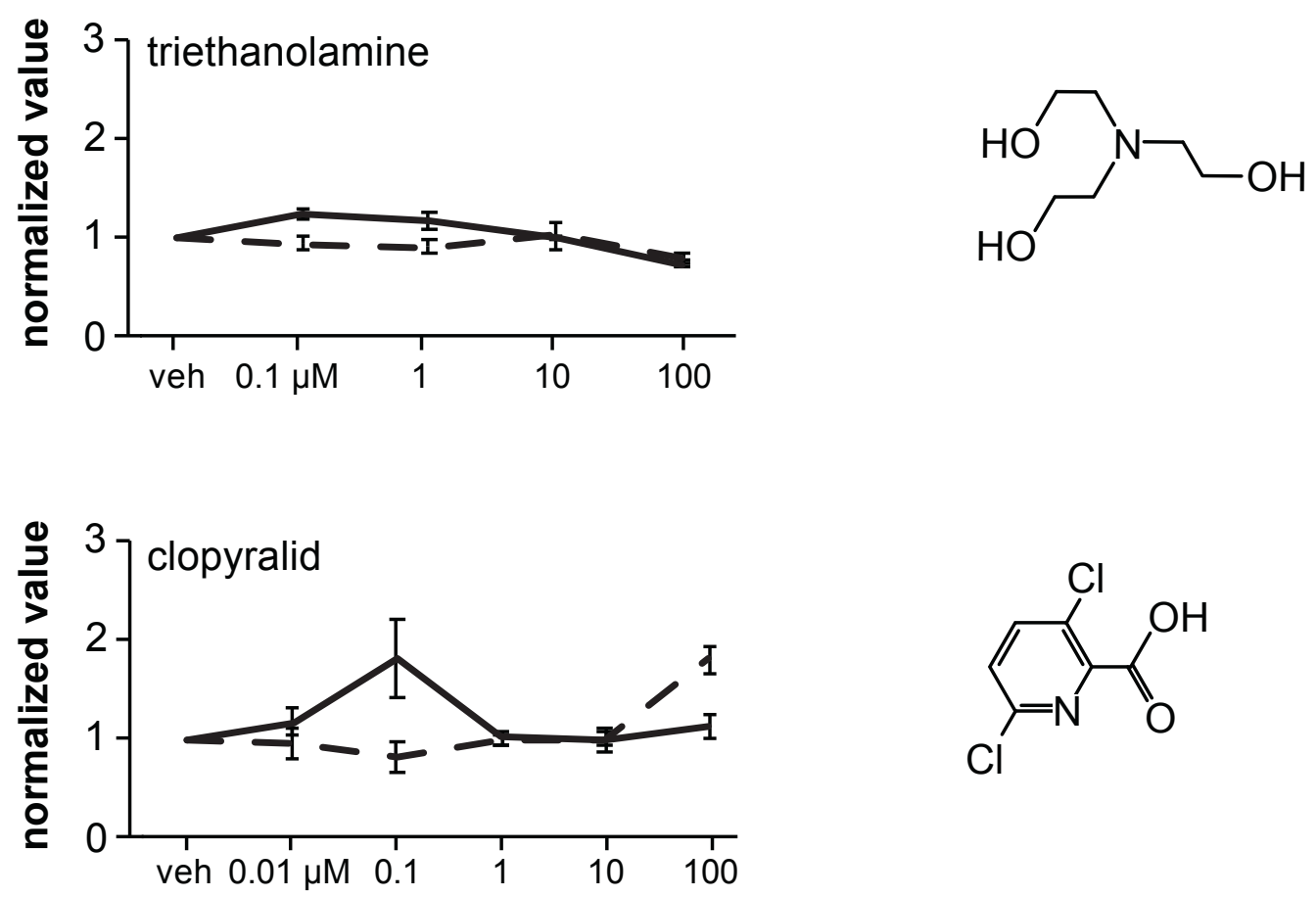